Research Article

\title{
High Glucose Level Disturbs the Resveratrol-Evoked Curtailment of CX3CL1/CX3CR1 Signaling in Human Placental Circulation
}

\author{
Dariusz Szukiewicz, ${ }^{1}$ Michal Pyzlak, ${ }^{1}$ Grzegorz Szewczyk, ${ }^{1}$ Aleksandra Stangret, ${ }^{1}$ \\ Seweryn Trojanowski, ${ }^{2}$ Michal Bachanek, ${ }^{2}$ Wojciech Braksator, ${ }^{3}$ and Jaroslaw Wejman ${ }^{4}$ \\ ${ }^{1}$ Department of General \& Experimental Pathology with Centre for Preclinical Research and Technology (CEPT), Second Faculty of \\ Medicine, Medical University of Warsaw, ul. Pawinskiego 3C, 02-106 Warsaw, Poland \\ ${ }^{2}$ Department of Obstetrics \& Gynecology, Second Faculty of Medicine, Medical University of Warsaw, ul. Kondratowicza 8, \\ 03-242 Warsaw, Poland \\ ${ }^{3}$ Department of Cardiology, Hypertension, and Internal Medicine, Second Faculty of Medicine, Medical University of Warsaw, \\ ul. Kondratowicza 8, 03-242 Warsaw, Poland \\ ${ }^{4}$ Department of Pathology, Professor Witold Orlowski Public Clinical Hospital, Medical Center for Postgraduate Education, \\ ul. Czerniakowska 231, 00-416 Warsaw, Poland
}

Correspondence should be addressed to Dariusz Szukiewicz; dariusz.szukiewicz@wum.edu.pl

Received 1 February 2017; Revised 1 April 2017; Accepted 26 April 2017; Published 1 June 2017

Academic Editor: Julio Galvez

Copyright (c) 2017 Dariusz Szukiewicz et al. This is an open access article distributed under the Creative Commons Attribution License, which permits unrestricted use, distribution, and reproduction in any medium, provided the original work is properly cited.

\begin{abstract}
Hyperglycemia-induced hyperactivity of chemokine CX3CL1 (fractalkine) occurs in the human placenta. Anti-inflammatory/ antioxidant activities of resveratrol (3,5,4'-trihydroxy-trans-stilbene) are related to the modulation of chemokine CX3CL1 and its receptor, CX3CR1, signaling pathways. We examined the influence of high glucose ( $25 \mathrm{mmol} / \mathrm{L}$ glucose; HG group; $N=36)$ on resveratrol-mediated effects on CX3CL1 and TNF- $\alpha$ production by the placental lobule, CX3CR1 expression and contents of CX3CR1, TNF- $\alpha$ receptor 1 (TNFR1), and NF- $\kappa$ B proteins in placental tissue. The placental lobules perfused under normoglycemic conditions formed the control NG group $(N=36)$. Resveratrol $(50$ and $100 \mu \mathrm{M}$; subgroups $\mathrm{B}$ and $\mathrm{C})$ administered into the perfusion fluid lowered the production of both CX3CL1 and TNF- $\alpha$. The reductions in CX3CL1 levels were more evident in the NG group. CX3CR1 expression was significantly higher in the NG subgroups B and C compared to the HG subgroups B and C (385.2 and 426.5\% versus 199.3 and 282.4\%, resp.). An increase in CX3CR1 protein content in placental lysates was observed in the NG subgroups B and C. Also, resveratrol significantly decreased NF- $\kappa$ Bp65 protein content only in the NG group, not affecting hyperglycemia-elicited TNFR1 upregulation. In conclusion, euglycemia assures optimal effects of resveratrol pertaining to CX3CL1/CX3CR1 signaling in the placenta. Future studies on resveratrol are needed, especially those including maternal-fetal risk assessments.
\end{abstract}

\section{Introduction}

Optimal control of glycemia should be considered in the context of homeostasis, including the preservation of a stable cytokine network in the vascular system [1]. A change in the balance between proinflammatory and anti-inflammatory cytokines, with increased release of the chemokine (chemotactic cytokine) CX3CL1 (fractalkine and neurotactin), in response to high-glucose conditions has been observed in many tissues and organs $[2,3]$. Such an inflammatory background may play a role in the pathogenesis and pathophysiology of diabetes $[2,4]$. Abnormal CX3CL1 signaling is associated with increased angiogenesis and accelerated atherosclerosis in hyperglycemic conditions [5, 6]. Moreover, CX3CL1 is considered a potential marker of the deterioration of pancreatic $\beta$-cell function in the islets of Langerhans [7]. 
Serum levels of CX3CL1 are associated with markers of insulin resistance in gestational diabetes [8]. Interestingly, it was recently demonstrated in mice that the deficiency of the CX3CL1 receptor CX3CR1 exerts a protective effect on glucose intolerance and insulin resistance [9]. The persistence of high glucose levels in diabetes and prediabetes promotes the production of reactive oxygen species, which aggravate oxidative stress and endothelial dysfunction [10].

Changes in the cytokine profile in response to hyperglycemia have been reported in placental circulation in diabetic pregnancies [11]. Since human placental vessels lack autonomic innervation, it is important to note that the humoral effects of vasoactive compounds (e.g., nitric oxide) that are produced locally by placental cells dominate the regulation of feto-placental blood flow, thus influencing vascular resistance [12]. Despite some controversies, both clinical observations and histopathological studies of the human placenta have confirmed an increased incidence of inflammatory reactions in diabetes $[5,11,13]$. Considering that the most important functions of the human placenta include immunosuppression to protect the fetal "allograft" from T-cellmediated immune aggression and infectious agents, the placental chemokine CX3CL1 may deserve special attention [14]. Together with certain other chemokines (CCL4, CCL7, and CCL14), CX3CL1 is involved in the processes of implantation, trophoblast invasion into the spiral uterine arteries, placental angiogenesis, response to inflammatory and immunologic factors within the utero-placental unit, and induction of labor [15-17].

Chemokine (C-X3-C motif) ligand 1 (CX3CL1) is encoded on the long arm of human chromosome 16 at position 13 and contains three exons. Unlike other chemokines, CX3CL1 is of nonhematopoietic origin; currently, CX3CL1 is the lone member of the $\mathrm{CX} 3 \mathrm{C}$ subfamily of chemokines ( $\delta$-chemokines) and possesses three amino acid residues between the first two cysteine residues [18]. CX3CL1 is synthesized as a membrane molecule consisting of the 76amino acid N-terminal chemokine domain, a 241-amino acid-glycosylated mucin-like stalk, a 21-amino acid hydrophobic transmembrane region, and a 37-amino acid intracellular C-terminal domain [19]. This protein can be cleaved by the lysosomal cysteine protease, cathepsin $S$, and by the members of the disintegrin and metalloproteinase (ADAMs) family, such as ADAM-10 and ADAM-17, which release a soluble form of CX3CL1 that contains the chemokine domain and the glycosylated mucin-like stalk [20]. Thus, CX3CL1 exists in a soluble form as a chemotactic protein for monocytes, natural killer (NK) cells, and T cells (but not neutrophils) and in a membrane-anchored form, mainly on endothelial cells, as a cell adhesion molecule. This set of properties, both a chemoattractant and an adhesive compound, makes CX3CL1 unique among other chemokines [21]. Moreover, CX3CL1 exerts cytotoxic effects on endothelial cells [22], which express substantial levels of CX3CL1; considering the additional synergistic effects of TNF- $\alpha$ and IFN- $\gamma$, almost every stimulus that influences cell homeostasis may induce CX3CL1 secretion $[21,22]$. The biological activities of CX3CL1 are mediated by its sole receptor CX3CR1 (previously denoted as V28), a G $\alpha$ i protein-linked seven- transmembrane receptor [19]. This receptor is localized on the surface of endothelial cells, mast cells, monocytes, macrophages, NK cells, platelets, subpopulations of T-lymphocytes, microglial cells, neurons, and smooth muscle cells [23]. In humans, for example, low surface expression of CX3CR1 is an indicative of the $\mathrm{CD} 14^{++}$and $\mathrm{CD} 16^{-}$monocyte subset, whereas high CX3CR1 expression corresponds to CD14 and $\mathrm{CD}_{16}{ }^{+}$monocyte populations $[23,24]$.

The stimulation of CX3CR1 will activate CX3CL1dependent and integrin-dependent migrations of cells with augmented adhesion as a result of synergistic reactions [23, 24]. Autoregulatory interactions between CX3CL1 and CX3CR1 may be driven by local changes in CX3CR1 expression. It was suggested that CX3CL1 autoactivates its own expression via the PI3-kinase/PDK1/Akt/NIK/IKK/nuclear factor kappa $B(N F-\kappa B)$ signaling pathway [25]. Tumor necrosis factor alpha (TNF- $\alpha$ ) also induces the expression of CX3CL1 and CX3CR1 in rat aortic smooth muscle cells via the NF- $\kappa$ B pathway [26]. The human protein encoded by the TNFRSF1A gene is one of the major receptors for TNF- $\alpha$, and TNFR1 (CD120a) can be detected in almost all cell types, including endothelial cells [26, 27]. Signaling induced by the stimulation of TNFR1 is involved in the activation of NF- $\kappa$ B transcription, the modulation of inflammatory responses, and apoptosis [27].

Resveratrol, a trihydroxy derivative of stilbene (3,5,4'-trihydroxy-trans-stilbene) that exists in isomeric trans and cis forms, is a naturally occurring polyphenolic phytoalexin that can be isolated from red grapes (predominantly from grape skin), berries, peanuts, and red wine [28]. This compound possesses anti-inflammatory and antioxidant properties related to its interference with the NF- $\kappa \mathrm{B}$ and JAK/STAT signaling pathways, which regulate the expression of various genes involved in inflammation, including CX3CL1 [28, 29]. Moreover, it has been demonstrated that resveratrol suppresses TNF- $\alpha$-induced CX3CL1 activity in endothelial cells [30]. The abovementioned properties may be of particular therapeutic relevance in metabolic disorders with an inflammatory background. The harmful effects of hyperglycemiarelated changes in the cytokine profile have been observed in placental circulation, including in endothelial cells and vascular smooth muscle cells $[11,31]$.

In this study, we examined the influence of resveratrol on CX3CL1 and TNF- $\alpha$ production in extracorporeally perfused human term placental lobules under hyperglycemic (25 mmol/L glucose; HG group; $N=36$ ) and normoglycemic ( $5 \mathrm{mmol} / \mathrm{L}$ glucose; NG group; $N=36$ ) conditions. Endothelial CX3CR1 expression in the placental microvasculature and contents of CX3CR1, TNFR1, and NF- $\kappa \mathrm{B}$ proteins in the perfused placental tissue were also examined in the studied groups.

\section{Materials and Methods}

The study was conducted in compliance with the international and local laws of human experimentation, and the project was officially approved by the local Ethics Committee of the Medical University of Warsaw (Ethical Clearance Approval no. KB21/2011). A written informed consent has 
TABLE 1: Clinical characteristics of the two studied groups.

\begin{tabular}{|c|c|}
\hline Parameter & HG group (high glucose), NG group (normal glucose) \\
\hline Number of patients/newborns/placentae/isolated lobules $(N)$ & $36 / 36 / 36 / 36$ per group \\
\hline Age of the patients in full years (range; mean; median) & $24-32,27,28$ \\
\hline Parity & 0 \\
\hline Gestational age in days (range; mean; median) & $269-285,277,278$ \\
\hline Method of delivery & Cesarean section \\
\hline Blood pressure during pregnancy & All records within normal range ${ }^{a}$ \\
\hline Proteinuria during pregnancy & Not present \\
\hline Liver blood tests (aminotransferases, enzymes AST and ALT levels) & Within normal range ${ }^{\mathrm{b}}$ \\
\hline Smoking during pregnancy & None declared active smoking \\
\hline Diabetes during pregnancy & Not present \\
\hline Body mass index $<21$ or $>35$ & None \\
\hline $\begin{array}{l}\text { Mother's blood (III trimester): hematocrit }(\mathrm{Ht}) \text {, hemoglobin }(\mathrm{Hb}) \text {, red blood } \\
\text { cell (RBC) count, mean corpuscular hemoglobin concentration }(\mathrm{MCHC})\end{array}$ & All within normal ranges ${ }^{c}$ \\
\hline Other identified risk factors & None \\
\hline Birth weight in grams (range; mean; median) & $2960-3790,3310,3350$ \\
\hline Sex of newborns $(\mathrm{M}-$ male, $\mathrm{F}-$ female $)$ & $19 \mathrm{M}+17 \mathrm{~F}$ \\
\hline Weight of placenta in grams (range, mean, median) & $545-774,655,663$ \\
\hline Weight of isolated lobule in grams (range, mean, median) & HG group: 84-113, 103, 100; NG group: 87-111, 102, 103 \\
\hline
\end{tabular}

been obtained from each woman whose placenta was used in the study. Strictly speaking, this work has been carried out in accordance with the Code of Ethics of the World Medical Association (Declaration of Helsinki) for experiments involving humans, and the Uniform Requirements for manuscripts submitted to Biomedical Journals have been fulfilled.

2.1. Placental Collection. The thirty-six heparinized placentae included in this study were obtained from previously nulliparous women after normal-course, singleton pregnancies delivered by elective cesarean section at term. The indications for cesarean section included breech presentation of the fetus and high-grade myopia in pregnant woman. The placentae were subjected to dual in vitro perfusion at $37^{\circ} \mathrm{C}$ using a modified Schneider's method $[32,33]$. Two nonadjacent lobules of similar size were selected and isolated from each placenta for simultaneous perfusion; the first lobule was exposed to hyperglycemic perfusion fluid (HG group), and the other lobule was subjected to perfusion with a normal concentration of glucose (NG group). More detailed clinical characteristics of these two homogenous groups are provided in Table 1. The chorionic vessels in the two selected lobules were cannulated immediately following delivery, and the placenta was transported on ice to the laboratory in a plastic box filled with cold, sterile phosphate-buffered saline (PBS). The perfusion was started not more than $20 \mathrm{~min}$ from the time of placental detachment.

2.2. In Vitro Perfusion of the Placental Lobules, Administration of Resveratrol. Each isolated placental lobule (two per placenta) was bilaterally perfused. A diagram of the two-sided closed extracorporeal perfusion system is shown in Figure 1. The experimental technique used in this study has been described in detail elsewhere [33]. Briefly, isotonic perfusion fluid (Krebs-Ringer with $200 \mathrm{mg} / \mathrm{L}$ cefazolin and $2 \mathrm{mg} / \mathrm{L}$ gentamicin) was buffered at $\mathrm{pH} 7.4$ (in PBS), and the extracorporeal fetal-side circuit perfusion process was strictly monitored to maintain perfusion pressure, flow stability, perfusion fluid volume, and hydrogen ion concentration within the range of allowable fluctuations, as shown in Table 2.

The perfusion fluid was enriched with a gas mixture containing $35 \% \mathrm{O}_{2}, 5 \% \mathrm{CO}_{2}$, and $60 \% \mathrm{~N}_{2}$. The oxygen concentration applied in the gas mixture provided a partial pressure of oxygen $\left(p \mathrm{O}_{2}\right)$ in the perfusion fluid of $13.3 \mathrm{kPa}$. The saturation value of dissolved oxygen was monitored throughout the experimental period by sampling the perfusion fluid at $30 \mathrm{~min}$ intervals between 30 and $120 \mathrm{~min}$ of perfusion. Polarographic Clark-type oxygen electrodes were mounted in the flow-through thermostatic chambers on both the fetal and maternal sides of the perfusion system (Figure 1). This type of $\mathrm{pO}_{2}$ electrode consists of an anode and cathode and measures oxygen tension amperometrically; the $\mathrm{pO}_{2}$ electrode produces a current at a fixed polarizing voltage $(-700 \mathrm{mV})$, which is directly proportional to the partial pressure of oxygen $\left(p \mathrm{O}_{2}\right)$ in the perfusate. The current evoked is a result of the subsequent reduction of oxygen at the cathode. The oxygen probes [Yellow Springs Instruments (YSI), IL, USA, model 05520-16] delivered the current to the twochannel biological oxygen monitor (YSI, model 5300A), 


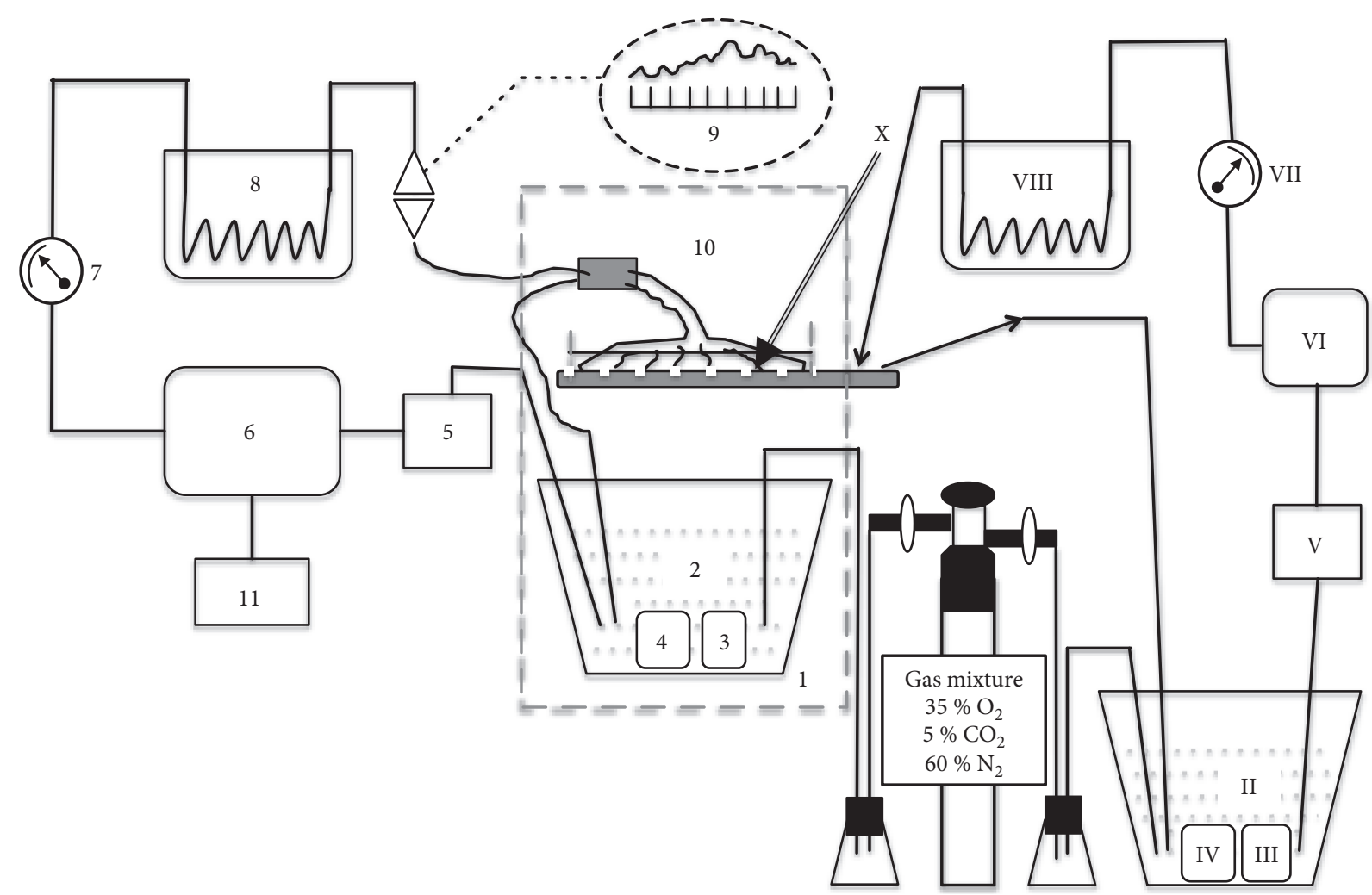

Figure 1: General scheme of in vitro dual placental perfusion system under normoxia. Elements of fetal side (Arabic numeration) and maternal side (Roman numeration) perfusion system: 1, I thermostatic chamber; 2, II reservoir; 3, III oxygen monitor with polarographic (Clark) oxygen electrodes; 4, IV pH meter; 5, V filter; 6, VI peristaltic pump; 7, VII flowmeter; 8, VIII thermostat; 9 Ludwig's manometer with kymograph; 10, X fetal and maternal compartments of perfusion chamber, 11 dosimetric pump.

TABLE 2: Criteria for monitoring of correctness of extracorporeal fetal-side placental perfusion.

(1) Perfusion pressure: after the adaptative phase, pressure should be maintained within $7-11 \mathrm{kPa}$. Avoidance of rapid changes in blood pressure. Pressure $<7 \mathrm{kPa}$ may be a result of vascular wall rupture. Pressure $>11 \mathrm{kPa}$ suggests occlusion (clot and embolus)

(2) Flow stability: flow velocity $15-20 \mathrm{~mL} / \mathrm{min}$ may change by no more than $\pm 10 \%$ within $30 \mathrm{~s}$

(3) Perfusion fluid volume: perfusion fluid loss after adaptive phase $\max .5 \mathrm{~mL} / \mathrm{h}$

(4) $\mathrm{pH}-\log \left[\mathrm{H}^{+}\right]$: after 30,90 , and 150 min of perfusion, $\mathrm{pH}$ should not be $<7.35,7.30$, and 7.25 in the arterial part of the system and at least $7.20,7.15$, and 7.10 in the venous part, respectively

which was connected to a computer-based data acquisition system.

Trans-tris methoxy resveratrol was purchased from Cayman Chemical Comp., USA, (catalogue number 10188) as a crystalline solid. For maximum solubility in aqueous buffers, trans-tris methoxy resveratrol was dissolved in dimethyl sulfoxide (DMSO) and then diluted with PBS to obtain the three desired concentrations (10, 50, and $100 \mu \mathrm{M})$ for the respective subgroups (A, B, and C). After $60 \mathrm{~min}$ of placental perfusion, $5 \mathrm{~mL}$ boluses of resveratrol was administered into the circuits on both the fetal and maternal sides at $30 \mathrm{~min}$ intervals.

The respective hyperglycemic and normoglycemic controls perfused without resveratrol have been established during the preliminary phase of this study.

2.3. Measurements of CX3CL1 and TNF- $\alpha$. During the $150 \mathrm{~min}$ perfusion, including the initial $30 \mathrm{~min}$ adaptive phase, basal [immediately before the administration of lipopolysaccharide (LPS)] and LPS-evoked $(10 \mathrm{ng} / \mathrm{mL})$ CX3CL1 released into the fetal-side placental circulation was examined quantitatively in perfusion fluid samples by ELISA. The RayBio Human Fractalkine ELISA Kit (RayBiotech Inc., USA, catalogue number ELH-Fractalkine) applied in this study has a very high specificity that exceeds most other available ELISA tests for the detection of CX3CL1 in placental perfusates, to the best of our knowledge. According to the manufacturer's information, the minimum detectable dose of CX3CL1 for this test is typically less than $300 \mathrm{pg} / \mathrm{mL}$, and cross-reactivity was not observed with any of the cytokines tested including human angiogenin, BDNF, BLC, ENA-78, FGF-4, IL- $1 \alpha$, IL- $1 \beta$, IL-2, IL-3, IL-4, IL-5, IL-7, IL-8, IL-9, IL-10, IL-11, IL-12 p70, IL-12 p40, IL-13, IL-15, IL-309, IP10, G-CSF, GM-CSF, IFN- $\gamma$, leptin, MCP-1, MCP-2, MCP3 , MDC, MIP- $1 \alpha$, MIP- $1 \beta$, MIP- $1 \delta$, PARC, PDGF, RANTES, SCF, TARC, TGF- $\beta$, TIMP- 1 , TIMP- 2 , TNF- $\alpha$, TNF- $\beta$, TPO, 
and VEGF (see Abbreviations). The samples of the perfusion fluid were collected every $30 \mathrm{~min}$ from 30 to $150 \mathrm{~min}$. The mean values for each group and at each time point were calculated.

The dose of LPS administered in this study was precisely titrated during the preliminary phase of the perfusion experiments. Based on the series of dose-response approaches (the dose-response curve analyses), $10 \mathrm{ng} / \mathrm{mL}$ was established as the mean dose of LPS eliciting $45-55 \%$ maximal TNF- $\alpha$ response (data not shown). Thus, the administration of LPS was an approach to standardize the inflammatory response.

In addition to CX3CL1 assessments, TNF- $\alpha$ levels in the perfusate samples obtained at the same time points were examined. Commercially available kit was used (RayBio Human TNF-alpha ELISA Kit; catalogue number ELHTNFalpha-001) according to the manufacturer's instructions. The minimum detectable dose of TNF- $\alpha$ amounted to less than $10 \mathrm{pg} / \mathrm{mL}$.

As a form of control in relation to these above measurements (CX3CL1 and TNF- $\alpha$ ), we used our unpublished data from the previous perfusions of 16 placental lobules ( 8 with hyperglycemic and 8 with normoglycemic perfusion fluid) in the same manner, except the administration of resveratrol.

2.4. Detection and Quantification of NF- $\kappa B$ in Perfused Placental Tissue. To compare the influence of different doses of resveratrol on NF- $\kappa \mathrm{B}$ signaling in the high-glucose and normal-glucose groups, NF- $\kappa$ Bp65 protein content was quantified in placental (perfused lobule) tissue homogenates following the termination of the perfusion experiments. The NF- $\kappa$ Bp 65 (total) ELISA kit (Invitrogen Corp., Camarillo, CA, USA; catalogue number KHO0371) designed to detect and quantify the level of NF- $\kappa$ Bp 65 regardless of phosphorylation state was used. Before obtaining a lysate, the tissue was cut into approximately $1 \mathrm{~mm}^{3}$ cubes using a razor blade on a glass plate on ice. To gently disrupt the cells, the cubes were transferred into a handheld Potter $S$ homogenizer (Sartorius $^{\mathrm{TM}}$ Stedim Biotech $\mathrm{GmbH}$ ). Ice-cold phosphoprotein lysis buffer containing $4 \mathrm{mM}$ sodium pyrophosphate, $50 \mathrm{mM}$ HEPES, $100 \mathrm{mM} \mathrm{NaCl}, 10 \mathrm{mM}$ EDTA, $10 \mathrm{mM} \mathrm{NaF}$, $2 \mathrm{mM} \mathrm{NaVO}_{4}, 1 \mathrm{mM}$ PMSF, $10 \%$ Triton X-100, $5 \mu \mathrm{g} / \mathrm{mL}$ leupeptin, and $5 \mu \mathrm{g} / \mathrm{mL}$ aprotinin was used. The liquefied tissue was poured into $1.5 \mathrm{~mL}$ tubes, and the tissue and cell debris were removed by centrifugation at $10,000 \times \mathrm{g}$ for $3 \mathrm{~min}$ at $4^{\circ} \mathrm{C}$. The cleared supernatant was subjected to in vitro quantitative measurements of $\mathrm{NF}-\kappa \mathrm{Bp} 65$ protein using 96-well plates and a microplate reader. Based on the information provided by the manufacturer, the NF- $\kappa$ Bp 65 protein levels detected in this manner are consistent with the results obtained by Western blot analysis. The p50 $(\mathrm{NF}-\kappa \mathrm{B} 1) / \mathrm{p} 65$ (RelA) heterodimer assessed in this ELISA kit is the most abundant form of NF- $\kappa \mathrm{B}$ [34]. The assay has no cross-reactivity with either $\mathrm{NF}-\kappa \mathrm{Bp} 50$ or $\mathrm{I} \kappa \mathrm{B} \alpha$, but cross-reactivity with other NF- $\kappa \mathrm{B}$ family members was not evaluated. The minimum detectable level of NF$\kappa$ Bp65 protein was $50 \mathrm{pg} / \mathrm{mL}$, and the detection range was $78-5000 \mathrm{pg} / \mathrm{mL}$.

The experimental setup for the perfusion procedures, the administration of LPS and resveratrol, and the CX3CL1 and TNF- $\alpha$ measurements at fixed time points is presented in Figure 2.

2.5. CX3CR1 Immunostaining. After completing the perfusion procedure, a single specimen was excised in a standardized manner from each perfused lobule from the region contiguous with the fetal surface of the placenta. Following formalin fixation and paraffin embedding, three $5 \mu \mathrm{m} \mathrm{sec}$ tions were obtained from each specimen/examined lobule. The methodology for the in vitro experiment precluded obtaining placental tissue specimens during the perfusion phase. Thus, the data on CX3CR1 expression were not collected at the same time points as those for the CX3CL1 and TNF- $\alpha$ data. However, as a control measurement, CX3CR1 immunostaining was performed on tissue specimens collected from each perfused placental lobule at the end of the adaptive period ( $30 \mathrm{~min}$ ) and utilized as an initial (init.) measurement of CX3CR1 expression in the high-glucose and normal-glucose environments (groups HG and NG, resp.).

The standard immunohistochemical procedures were applied to visualize CX3CR1. Rabbit polyclonal antibody IgG to CX3CR1 (ab8020; Abcam Inc., USA; $10 \mu \mathrm{g} / \mathrm{mL}$ ) was used as the primary antibody, and goat anti-rabbit IgG was used as the biotinylated secondary antibody (ab64256; Abcam; $0.5 \% v / v)$. The primary antireceptor antibodies were visualized using a StreptAB-Complex/HRP Duet Kit (Dako Cytomation, Glostrup, Denmark) following the procedure recommended by the manufacturer, with 3,3'-diaminobenzidine as the chromogen. In the negative controls, the polyclonal primary antibody was replaced with normal rabbit preimmune IgG diluted in PBS containing 3\% bovine serum albumin at the same protein concentration.

2.6. Mean Density of Placental Microvessel Network. In view of the fact that CX3CR1 is also expressed in vascular endothelial cells, it was presumed that the accuracy of CX3CR1 expression measurement might be significantly influenced by the local differences in density of placental microvessels [35-37]. To avoid this discrepancy in the results, the identification of the vasculature elements in placental sections was performed using endothelial cell maker, rabbit polyclonal antibody anti-CD31 (dilution $1: 50$, Abcam Inc., Cambridge, MA, USA; ab28364). Next, a biotinylated goat anti-rabbit antibody was used as the secondary (Abcam Inc.).

The technique of the mean density of placental vessels assessment was described in detail elsewhere [38, 39]. Briefly, using light microscopy with computed morphometry for quantitative analysis (Quantimet 500C+ image analysis workstation provided by Leica, UK), the vascular/extravascular tissular index (V/EVTI) was estimated in calibrated areas of the placental sections. Each specimen (paraffin section) underwent three area analyses repeated by two experienced, independent observers. The single area measured with the picture analyzer amounted to $685199 \mu \mathrm{m}^{2}$ and the total number of specimens 36 per group. The picture analysis procedure consisted in a measurement of the total vascular area. Consequently, the total lumen area of all types of identified vessels was summed up in both groups. With the purpose of a minimizing disruption caused by 


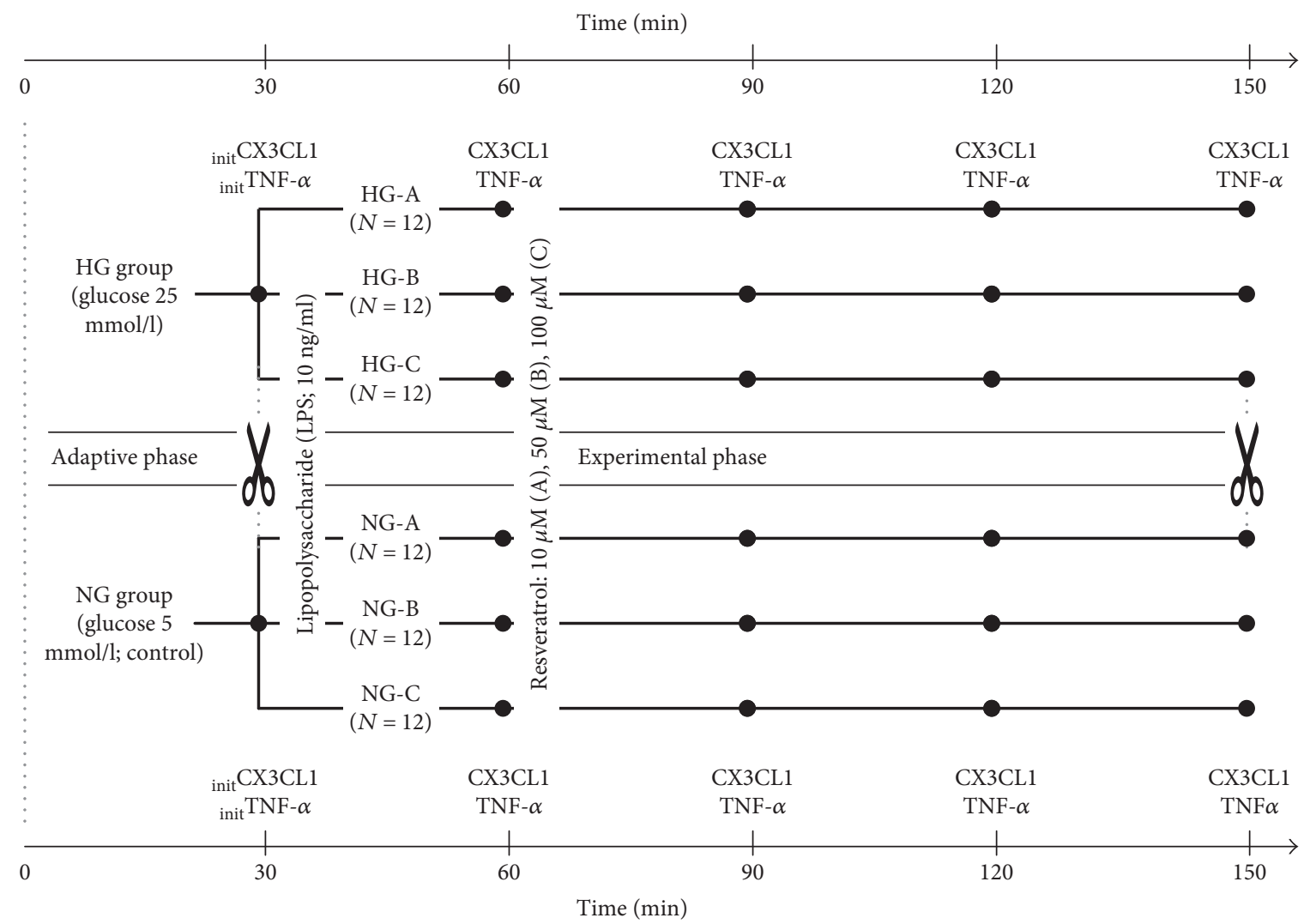

FIgURE 2: The experimental setup of the perfusion procedures with measurement time points for CX3CL1 and TNF- $\alpha$ (marked with dots). The initial concentrations of CX3CL1 and TNF- $\alpha$ were measured at the end of adaptive phase ${ }_{\text {init }}$ CX3CL1 and ${ }_{\text {init }}$ TNF- $\alpha$, resp.). Time points for the collection of the placental specimens are marked with scissors icon.

technical errors, especially unaxial section of the vessel, the lowest value of Ferret's diameter was accepted as the diameter of single lumen. Thus, V/EVTI represents the ratio, which reflects the intensity of vascularization and is most closely correlated with the mean density of placental microvessels.

\subsection{CX3CR1 Expression: Quantitative Immunohistochemical} Analysis. CX3CR1-immunostained paraffin sections of the placental lobule specimens were subjected to quantitative immunohistochemistry using morphometric software (Quantimet 500C+, Leica, UK). Light microscopy was applied to capture the images. All morphometric procedures were carried out twice by two independent researchers, and the average values were recorded. The intensity of immunostaining was evaluated through two parameters: the mean color saturation and thresholding in grey level histograms. Thus, the expression of CX3CR1 corresponded to the total immunostained calibrated area of the sections examined, where color saturation was treated as the segmentation criteria for objects. The total analysed area of the single image was $138246 \mu \mathrm{m}^{2}$ at $200 \mathrm{x}$ magnification. In each group, 108 visual fields were analysed (three visual fields per each isolated lobule). To achieve the maximum accuracy of the measurements, stability of power supply during morphometric procedures was assured by the power supply unit (Seasonic Platinum-1050, USA) and controlled with professional LCR
(L-inductance, $\mathrm{C}$-capacitance, and $\mathrm{R}$-resistance) digital multimeter (CEM 9935, China) using back-probing power connectors of the computer's motherboard. The process of warming up and operating temperature (allowed range: $40-55^{\circ} \mathrm{C}$ ) of the central processing unit (CPU) were monitored with a dedicated software (Core Temp 1.0 RC6 freeware, Arthur Lieberman). Other parameters, including illumination, shading correction, hue, averaging of image intake, luminescence, and the relation of illumination to quantification of area percentage of positively staining structures were standardized and monitored at the level of the morphometric software as described previously $[33,40]$. Finally, the results obtained for the specimens examined were adjusted for the mean density of the placental microvessel network. The morphometric results that included the $90 \%$ confidence intervals were reported as the mean percentage values \pm SEM.

2.8. CX3CR1 Expression: CX3CR1 Protein Content in the Perfused Placental Tissue Homogenates. For the comparative assessment of placental CX3CR1 expression independent of endothelial cells and the mean vascular density, CX3CR1 protein levels were quantified in the placental (the perfused lobule) tissue homogenates following the termination of the perfusion experiments. The Human CX3CR1 ELISA Kit (sandwich ELISA; LifeSpan BioSciences Inc., Seattle, WA, 
USA; catalogue number LS-F9187) was used, with a detection range of $0.156-10 \mathrm{ng} / \mathrm{mL}$ and a sensitivity of $<0.055 \mathrm{ng} / \mathrm{mL}$, as declared by the manufacturer.

Before obtaining a lysate, the tissue was cut into approximately $1 \mathrm{~mm}^{3}$ cubes using a razor blade on a glass plate on ice. To gently disrupt the cells, the cubes were transferred into a handheld Potter S homogenizer (Sartorius Stedim Biotech $\mathrm{GmbH}$ ). Ice-cold phosphoprotein lysis buffer containing $4 \mathrm{mM}$ sodium pyrophosphate, $50 \mathrm{mM}$ HEPES, $100 \mathrm{mM} \mathrm{NaCl}$, $10 \mathrm{mM}$ EDTA, $10 \mathrm{mM} \mathrm{NaF}, 2 \mathrm{mM} \mathrm{NaVO}_{4}, 1 \mathrm{mM}$ PMSF, $10 \%$ Triton $\mathrm{X}-100,5 \mu \mathrm{g} / \mathrm{mL}$ leupeptin, and $5 \mu \mathrm{g} / \mathrm{mL}$ aprotinin was used. The liquefied tissue was poured into $1.5-\mathrm{mL}$ tubes, and the tissue and cell debris were removed by centrifugation at $10,000 \times \mathrm{g}$ for $3 \mathrm{~min}$ at $4^{\circ} \mathrm{C}$.

Placental tissue lysates were obtained as described for the assessment of NF- $\kappa$ Bp65 protein levels (Section 2.4). Then, the cleared supernatant was subjected to in vitro quantitative measurements of CX3CR1 protein using 96-well plates and a microplate reader.

\subsection{TNFR1/TNFRSF1A Protein Content in the Perfused} Placental Tissue Homogenates. For the comparative assessment of TNF- $\alpha$ receptor type 1 (TNFR1/TNFRSF1A and CD120a) expression in perfused lobule tissue, placental homogenates were prepared after the termination of the perfusion experiments. The liquefied tissue was obtained in the same manner as described above for the CX3CR1 ELISA Kit. Then, the homogenates were centrifuged for 5 minutes at $5000 \times \mathrm{g}$, and the cleared supernatant was subjected to in vitro quantitative measurements of TNFRSF1A protein using 96-well plates and a microplate reader. The Human ELISA Kit for tumor necrosis factor receptor superfamily, member 1A (TNFRSF1A; sandwich ELISA; Cloud-Clone Corp., Wuhan, People's Republic of China catalogue number SEB499Hu) was used, with a detection range of 15.6$1000 \mathrm{pg} / \mathrm{mL}$ and a sensitivity of $<6.5 \mathrm{pg} / \mathrm{mL}$, as declared by the manufacturer.

2.10. Statistical Analysis. Mann-Whitney $U$ test was applied. The results are expressed as the mean \pm SEM, medians, or mean percentage values \pm SEM. The differences between the two groups (high-glucose versus normoglycemic conditions) were deemed statistically significant if $p<0.05$.

\section{Results and Discussion}

There is a growing body of evidence indicating that the biological properties of resveratrol may be translated into beneficial pharmacologic activities in cardiovascular diseases, including these coexisting hyperglycemic states [30, 41, 42]. Thus, the ability of resveratrol to counteract the increasing deterioration of endothelial cell function related to local CX3CL1 overproduction and/or altered CX3CR1 expression may be crucial $[42,43]$. The CX3CL1 levels are shown in Table 3 (see also the experimental setup in Figure 2).

There were no significant differences in the initial concentration of CX3CL1 ( ${ }_{\text {init }}$ CX3CL1) between the placentae perfused with hyperglycemic perfusion fluid and those perfused with normoglycemic perfusion fluid. The mean init $\mathrm{CX} 3 \mathrm{CL} 1$ was $93.8 \pm 24.2 \mathrm{pg} / \mathrm{mL}$ in the $\mathrm{HG}$ group and $96.3 \pm 23.0 \mathrm{pg} / \mathrm{mL}$ in the NG group. The median, rounded to the nearest whole number, was 84 [95\% confidence interval (CI) 55-125] pg/mL in the HG group and 82 (95\% CI 54120) $\mathrm{pg} / \mathrm{mL}$ in the NG group (Table 3). During the $120 \mathrm{~min}$ observation period including four perfusion fluid specimen collections, the mean CX3CL1 concentration significantly increased in both groups. The addition of LPS to the perfusion fluid evoked a significantly $(p<0.05)$ stronger response in the HG group, and the mean CX3CL1 levels were significantly higher in the HG group than in the NG group at every measurement. Based on the comparisons of the mean CX3CL1 levels and the dynamics of the increase in CX3CL1 levels at consecutive time points between subgroups HG-A and NG-A and the respective controls [hyperglycemic and normoglycemic perfused without resveratrol (HG-RF and NG-RF, resp.; see Table 3)], we concluded that $10 \mu \mathrm{M}$ resveratrol does not affect CX3CL1 production. Although CX3CL1 levels were consistently higher in the HG group compared to the NG group, higher doses of resveratrol (50 and $100 \mu \mathrm{M}$ ) lowered CX3CL1 production in a dose-dependent manner in both groups (see subgroups HG-B, HG-C, NG-B, and NG-C in Table 3). This effect was more evident in perfusion fluid specimens obtained from the normoglycemic group, where the percent reductions in CX3CL1 levels after the administration of the highest dose of resveratrol (subgroup NG-C) amounted to 22.10, 54.79, and 60.04\% (at 90, 120, and $150 \mathrm{~min}$, resp.), versus $10.11,32.65$, and $37.63 \%$ in the hyperglycemic subgroup C. These data also show that the activity of resveratrol accrues over time within the period of $60 \mathrm{~min}$. The results of the present comparative study focused on CX3CL1/CX3CR1 signaling in high-glucose versus normal-glucose environments may be useful for better understanding these complex relationships in the context of the potential therapeutic applications of resveratrol. To the best of our knowledge, this is the first publication on these issues pertaining to humans. The significantly higher levels of CX3CL1 in the HG group after LPS administration suggest that the hyperglycemic environment sensitizes perfused placental tissues to proinflammatory stimuli; the initial production of CX3CL1 was comparable in the two groups. Even after taking into account that LPS administration elicited higher CX3CL1 levels in the HG group compared to the NG group, the effectiveness of resveratrol (at 50 and $100 \mu \mathrm{M}$ ) in decreasing CX3CL1 production (the percent reduction) by perfused placental lobules was significantly weakened in hyperglycemic conditions. It is worth mentioning that both hyperglycemia and inflammation influence proteolytic shedding on endothelial cells [44, 45]. Thus, further studies are needed to investigate whether observed changes in CX3CL1 levels are associated predominantly with the modulation of mRNA synthesis or proteolytic shedding.

The TNF- $\alpha$ levels in the perfusion fluid samples are summarized in Table 4.

Striking parallels were observed in the profiles of TNF$\alpha$ and CX3CL1 production. Similarly, LPS administration evoked a significantly greater $(p<0.05)$ increase in TNF$\alpha$ production in the HG group compared to the NG 


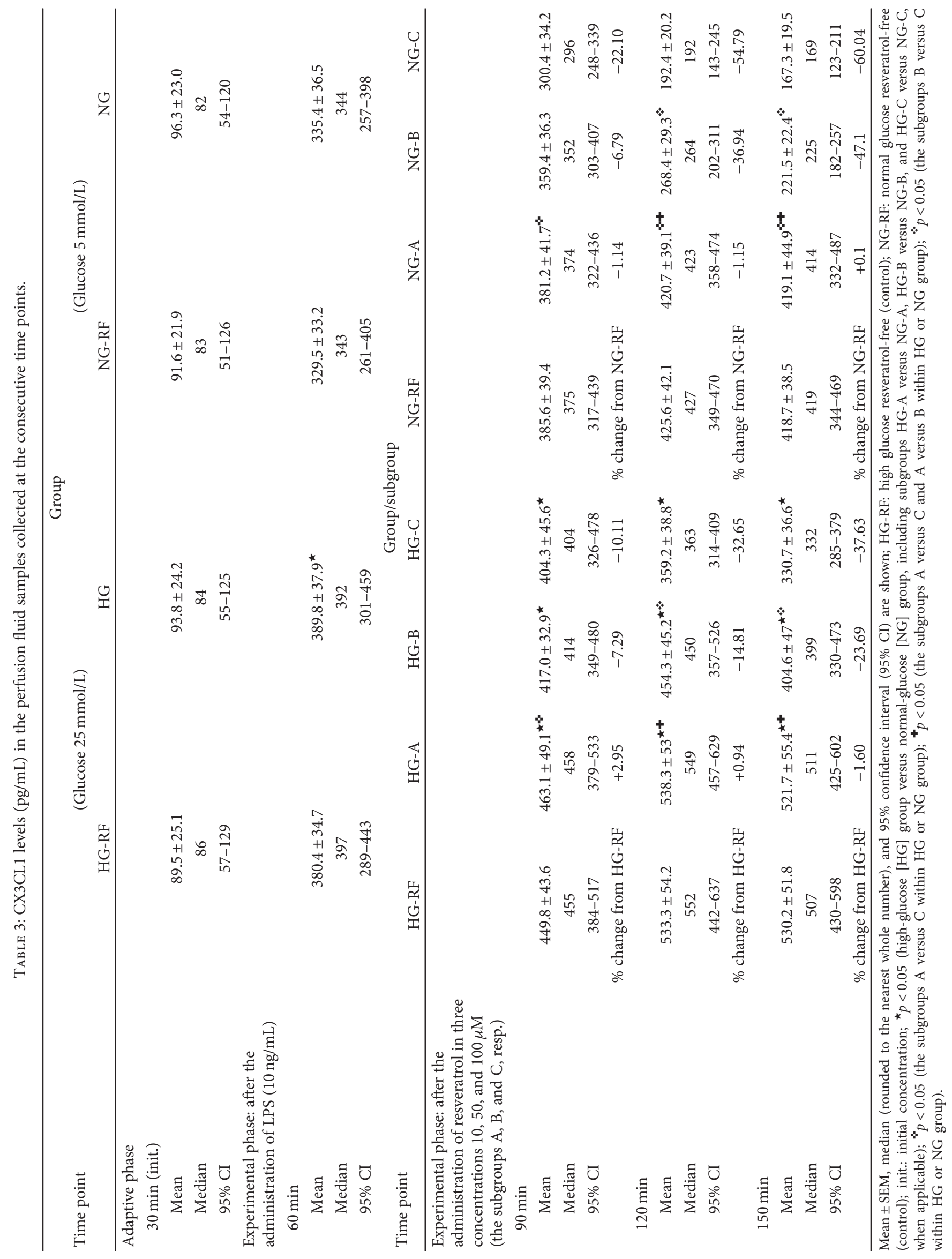




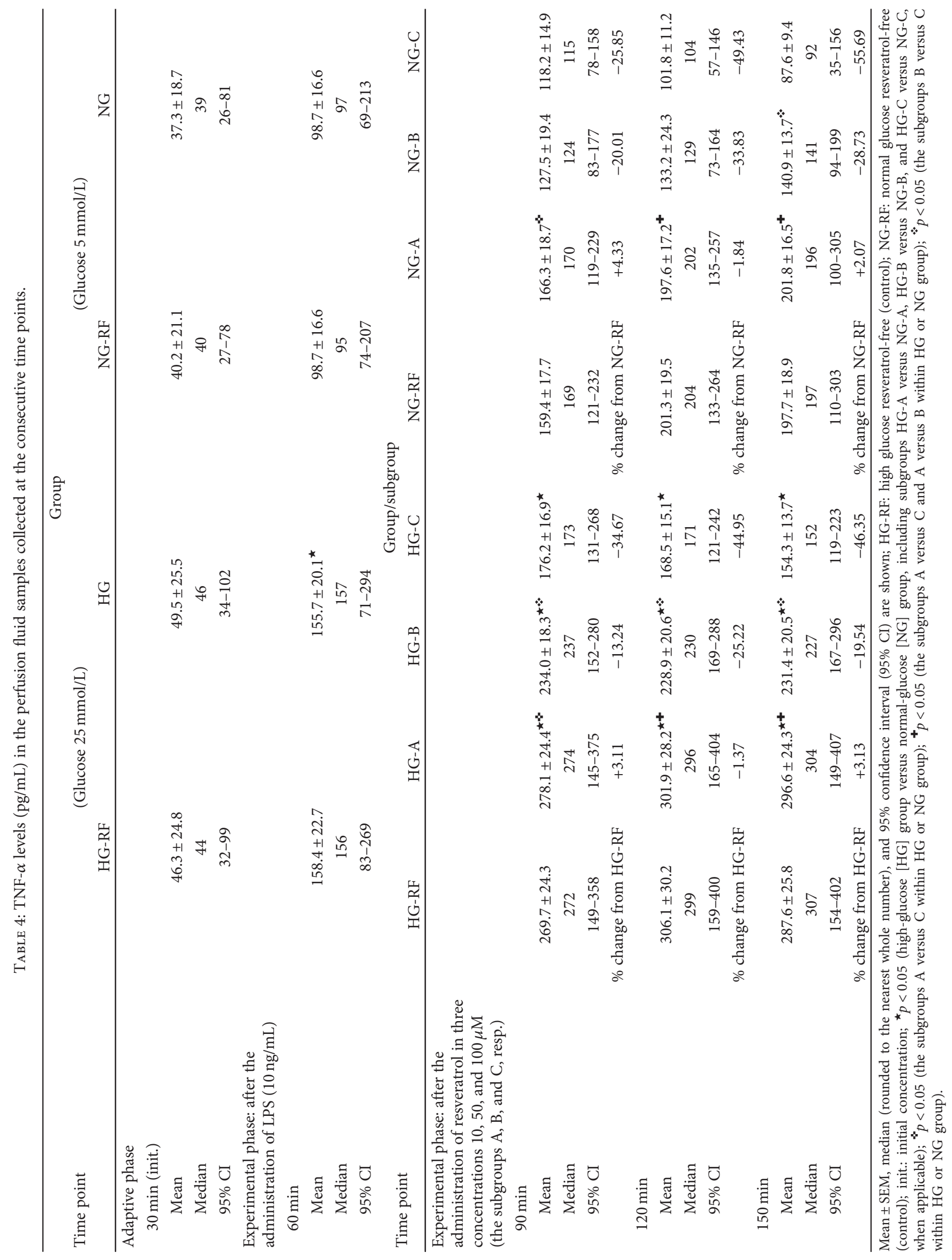


group. At the next time points $(90,120$, and $150 \mathrm{~min})$, the levels of TNF- $\alpha$ in subgroups HG-A, HG-B, and HG-C remained higher $(p<0.05)$ compared to those in subgroups NG-A, NG-B, and NG-C, respectively. Higher doses of resveratrol (50 and $100 \mu \mathrm{M}$ ) inhibited the production of TNF- $\alpha$ in a dose-dependent manner, whereas $10 \mu \mathrm{M}$ resveratrol did not show this inhibitory effect. TNF- $\alpha$ levels and the dynamics of the increase in TNF- $\alpha$ levels at consecutive time points were not significantly different $(p>0.05)$ between subgroups HG-A and NG-A and the respective resveratrol-free controls: hyperglycemic (HG-RF) and normoglycemic (NG-RF) (see Table 4).

In contrast to CX3CL1, the time-dependent increase (within $60 \mathrm{~min}$ ) in the inhibitory effect of 50 and $100 \mu \mathrm{M}$ resveratrol on TNF- $\alpha$ production in the perfused placental lobule was similar in the hyperglycemic and normoglycemic environments. The percent reductions in TNF- $\alpha$ levels for the highest dose of resveratrol were $25.85,49.43$, and $55.69 \%$ in subgroup NG-C and $34.67,44.95$, and $46.35 \%$ in subgroup HG-C (at 90, 120, and 150 min, resp.).

Because TNF- $\alpha$ is a strong inducer of CX3CL1 and influences CX3CR1 expression, the decelerated decrease in CX3CL1 levels under hyperglycemic conditions may reflect the modulation of CX3CR1 [22]. It is likely that the resveratrol-dependent reduction in TNF- $\alpha$ synthesis directly or indirectly triggers an autoregulatory mechanism that influences CX3CR1 expression in endothelial cells in response to the local decrease in CX3CL1 levels $[22,23]$.

The overall quality of CX3CR1 immunostaining in placental sections was sufficient for the application of standardized quantitative immunohistochemistry to investigate the expression of this receptor (Figure 3). Regions of the visual field demonstrating the strongest immunostainpositive reaction, captured from calibrated areas of the placental sections for computer image analysis, were to a large extent localized within the microvascular endothelium. This may confirm the appropriateness of analysing CX3CR1 expression in combination with V/EVTI. The differences in the initial expression of CX3CR1 were not significant between the groups, whereas resveratrol administration into the placental lobule vascular system after pretreatment with LPS significantly affected CX3CR1 expression in both groups (Figure 4). A positive correlation between resveratrol dose and CX3CR1 upregulation was documented in the NG group. The mean percent expression of CX3CR1 was significantly $(p<0.05)$ higher in subgroups NG-B and NG-C compared to subgroups HG-B and HG-C (385.2 and $426.5 \%$ versus 199.3 and $282.4 \%$, resp.). After treatment with the lowest dose of resveratrol $(10 \mu \mathrm{M})$, the mean percent expression of CX3CR1 was similar in hyperglycemic and normoglycemic placental sections $(228.7 \%$ in IA versus $221.6 \%$ in IIA).

Considering that $10 \mu \mathrm{M}$ resveratrol had no effect on CX3CL1 production in this study, LPS alone may be responsible for the upregulation of CX3CR1 in subgroups HG-A and NG-A. It is worth noting that in hyperglycemic subgroup $B$, the mean percent expression of CX3CR1 was similar (or even lower) than that in HG-A, while CX3CR1 expression was significantly upregulated in the normoglycemic subgroup $B$, with no significant difference compared to NG-C.

Thus, the increased mean CX3CR1 expression after resveratrol treatment may signify a dose-dependent compensatory mechanism. In all probability, the placental pool of endothelial cells dominates the other CX3CR1 compartments (other cell types) in placental tissue subjected to extracorporeal perfusion. The results obtained in the NG group (subgroups B and C) from quantitative CX3CR1 immunohistochemistry and CX3CR1 protein content measurements in the lysates (Figure 5(a)) indicate that a greater decrease in CX3CL1 production evokes higher (compensatory) expression of CX3CR1. Thus, the highest increase in mean CX3CR1 expression occurred in the normoglycemic subgroups. In the HG group, the discrepancy between the mean CX3CR1 expression in immunostained placental samples and the CX3CR1 protein content in the placental lysates may be explained by the fact that the mean microvascular density was considered and standardized using the V/EVTI parameter during the quantitative morphometry (see Section 2).

However, it is not clear whether the hyperglycemic environment itself upregulates CX3CR1/CX3CL1 signaling, as was reported in streptozotocin-induced diabetic rat kidneys [46].

The other placental lysates were used to determine NF$\kappa \mathrm{Bp} 65$ protein levels as an indicator of the protein complex that controls cellular responses and cell survival by cytokine production (Figure 5(b)). Higher doses of resveratrol (50 and $100 \mu \mathrm{M})$ significantly decreased NF- $\kappa$ Bp 65 protein content in placental tissue in the NG group in a dose-dependent manner, while the differences did not reach statistical significance in the HG group $(p>0.05)$. The placental tissue lysates from subgroups HG-A and HG-B contained the same amount of NF- $\kappa \mathrm{Bp} 65$ protein, further suggesting the lack of activity of $10 \mu \mathrm{M}$ resveratrol.

Hyperglycemia significantly influences a protein complex that controls DNA transcription, cytokine production, and cell survival and activates $\mathrm{NF}-\kappa \mathrm{B}$ via an aldose reductasecontrolled pathway [47]. Aldose reductase is considered an important factor in hyperglycemia-induced metabolic changes that lead to the development of secondary diabetic complications [48].

Interestingly, resveratrol reduces oxidative stress in diabetes through both deacetylation and inhibition of aldose reductase $[43,49]$. The deacetylation of NF- $\kappa$ Bp 65 is a direct consequence of sirtuin-1 (SIRT-1) activation by resveratrol [43]. Thus, a high-glucose environment may be a special target for the therapeutic implementation of resveratrol. In our study, the dose-dependent response of NF- $\kappa \mathrm{Bp} 65$ content in perfused placental tissue lysates to higher doses of resveratrol (50 and $100 \mu \mathrm{M}$ ) reached statistical significance $(p<0.05)$ only in the normoglycemic group. This difference between the groups may suggest that the antioxidant and anti-inflammatory potential of resveratrol is significantly reduced in a high-glucose environment. It is worth noting that NF- $\kappa$ Bp65 content in the lysates of placental tissue perfused without resveratrol (HG-RF and NG-RF; see Figure 5(b)) was similar in both groups, and the mean values 


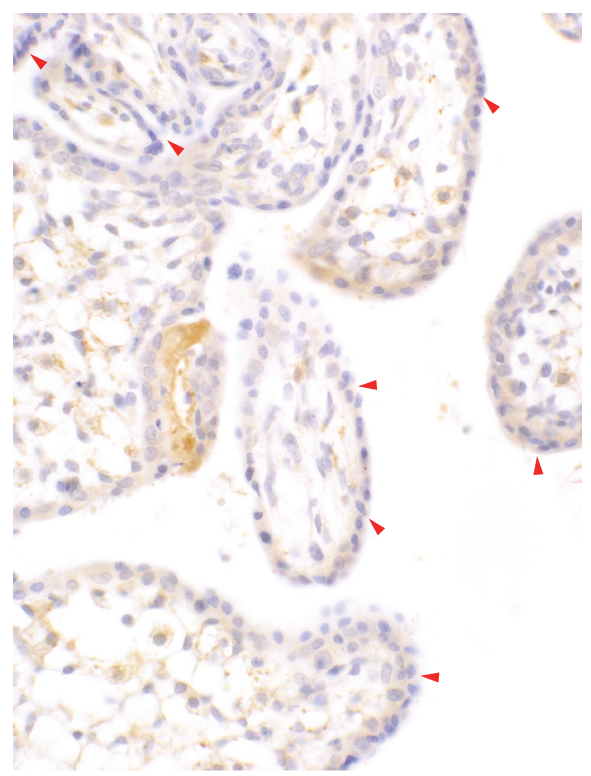

(a)

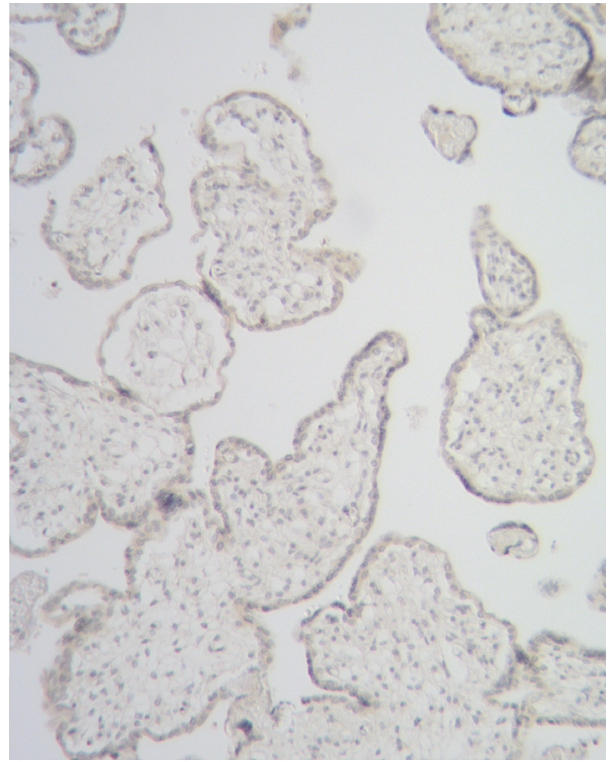

(b)

FIGURE 3: Immunohistochemical visualization of the receptor CX3CR1 in perfused placental tissue at 200x magnification (a) with the negative control ((b); mag. 100x). The image captured through optical microscope was digitally transformed for morphometric purposes. Immunostainpositive focal regions to a large extend correspond to the vascular endothelium (arrowheads). A single visual field observed with the naked eye looks substantially uniformly within each studied group. For that reason, only one immunostaining is presented for CX3CR1.

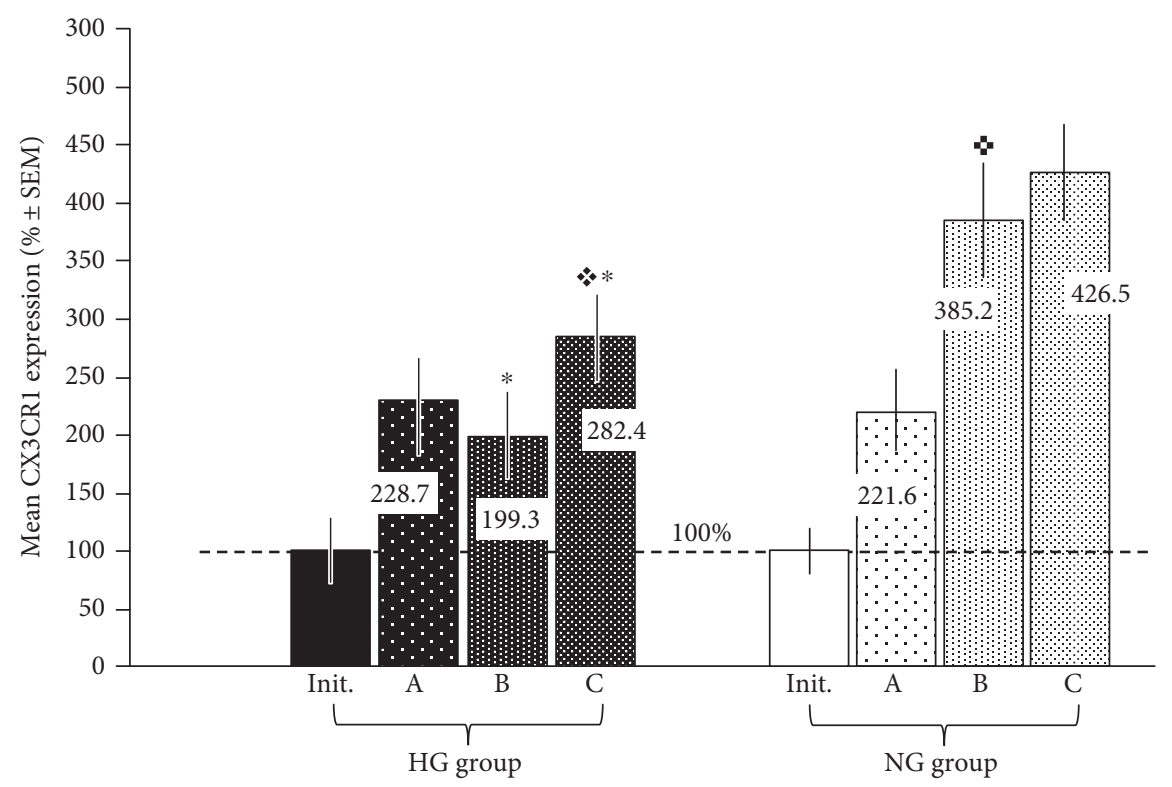

FIGURE 4: Effect of resveratrol administration on CX3CR1 expression. Resveratrol was given in three different doses (10, 50, and 100 $\mu \mathrm{M})$ in the respective subgroups $(\mathrm{A}, \mathrm{B}$, and $\mathrm{C})$, and the mean placental expressions of CX3CR1 in perfused human placental tissue under hyperglycemic (glucose $25 \mathrm{mmol} / \mathrm{L}$; HG group) and normoglycemic (glucose $5 \mathrm{mmol} / \mathrm{L}$; NG group) conditions have been analysed. The mean value of CX3CR1 expression in the specimens obtained at the end of the adaptive period (before the administration of LPS; see Figure 2.) was treated as the initial (init.) and taken as $100 \%$ in each group. * indicates $p<0.05$ (HG group versus NG group); ${ }^{*}$ indicates $p<0.05$ (HG subgroup C versus NG subgroup B); ${ }^{\boldsymbol{}}$ indicates $p<0.05$ (NG subgroup B versus NG subgroup A).

did not differ significantly from those reported for subgroups HG-A and NG-A. These data may seem unexpected because $\mathrm{NF}-\kappa \mathrm{B}$ belongs to the category of "rapid-acting" primary transcription factors, that is, factors that are present in cells in an inactive state and do not require new protein synthesis to become activated and thus modify cellular responses to harmful stimuli [50]. However, we used normal placentae derived from nondiabetic mothers in this 


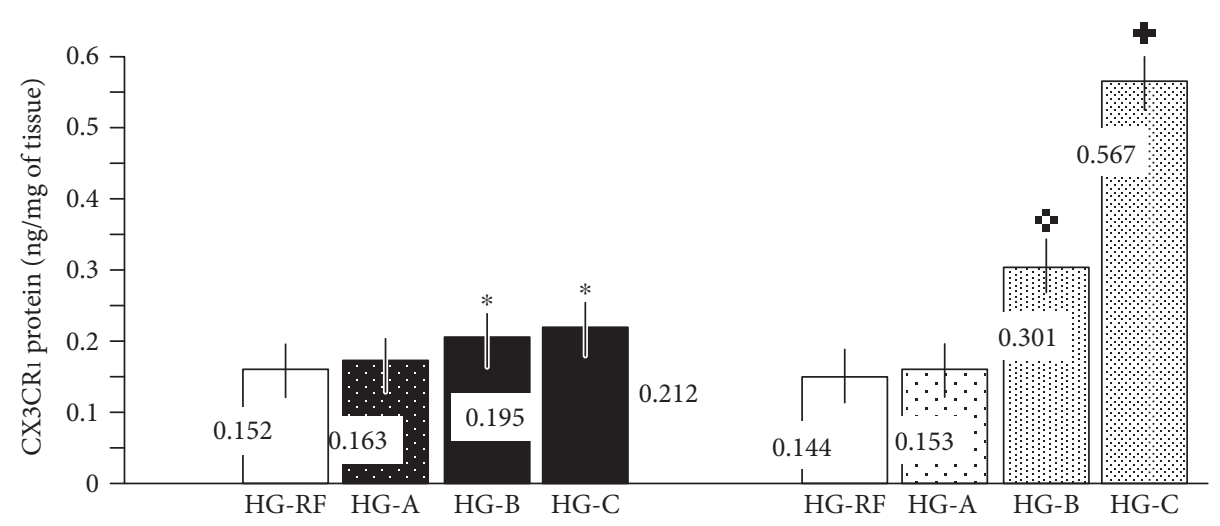

(a)

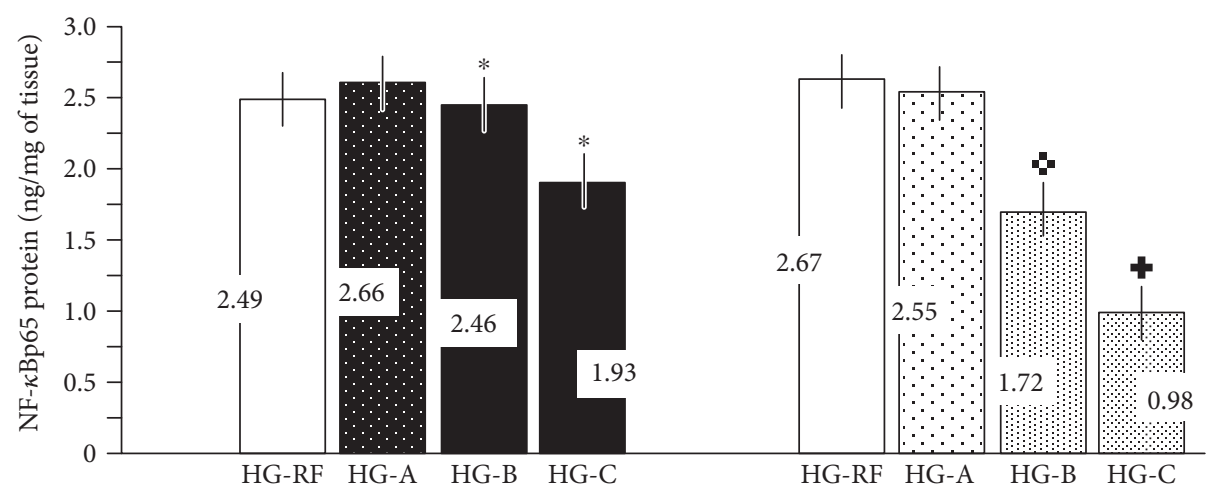

(b)

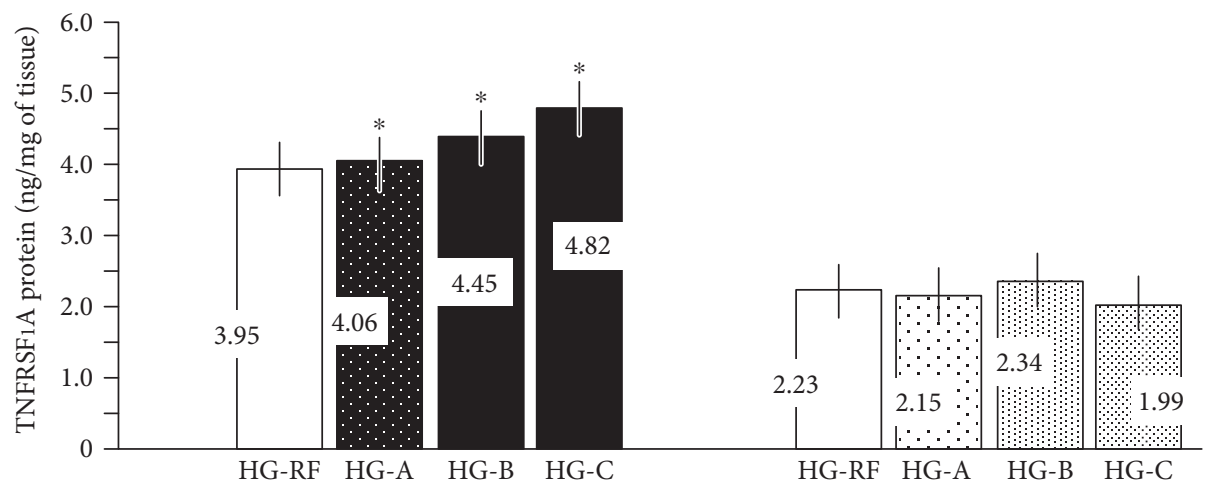

(c)

Figure 5: Contents of NF- $\kappa$ Bp65, CX3CR1, and TNFRSF1A ((a), (b), and (c), resp.) in the lysates of the placental tissue. High-glucose (HG-A, HG-B, and HG-C) versus normoglycemic (NG-A, NG-B, and NG-C) subgroups. Resveratrol-free controls (HG-RF and NG-RF) are also included. The isolated placental lobules were perfused under hyperglycemic (glucose $25 \mathrm{mmol} / \mathrm{L}$; HG group) and normoglycemic (glucose $5 \mathrm{mmol} / \mathrm{L}$; NG group) conditions after the administration of resveratrol in three different doses $(10,50$, and $100 \mu \mathrm{M})$ in the respective subgroups (A, B, and C). ${ }^{*} p<0.05$ (HG group versus NG group); ${ }^{*} p<0.05$ (NG subgroup B versus NG subgroup A); ${ }^{\boldsymbol{}} p<0.05(\mathrm{NG}$ subgroup $\mathrm{C}$ versus $\mathrm{NG}$ subgroup $\mathrm{B})$.

study. An increased protein content of NF- $\kappa \mathrm{B}$ family members has been reported in tissues, including the placenta, from diabetic patients [51, 52].

Finally, we observed a significant difference $(p<0.05)$ in TNFRSF1A protein levels in placental lysates from the two groups (Figure 5(c)). In contrast to CX3CR1 and CX3CL1 production, the decrease in TNF- $\alpha$ production in response to resveratrol $(50$ and $100 \mu \mathrm{M})$ did not significantly affect TNFRSF1A protein content in the perfused placental tissue.
The mean TNFRSF1A protein concentration was higher in the hyperglycemic environment (HG group) than in the normoglycemic environment (NG group). The differences between the respective subgroups (A, B, and $\mathrm{C}$ ) within groups $\mathrm{HG}$ and NG were not significant, suggesting no effect of resveratrol on TNFRSF1A expression. In this situation, hyperglycemic conditions per se may be responsible for the consistently higher TNFRSF1A protein expression in all placental tissues obtained from group I $[10,53]$. Alternatively, 
the content of this ubiquitous protein, one of the major receptors for TNF- $\alpha$, in perfused placental tissue lysate may not reflect more subtle changes (e.g., in vascular endothelial cells), and perhaps another approach, such as a different research model, is needed in future studies. It is important to note that TNFRSF1A exists as both a cell surface receptor (the membrane-bound form; mTNFRSF1A) and a soluble protein (sTNFRSF1A) that competes with TNF- $\alpha$ for receptor sites on cells [27]. The replacement of circulating blood with perfusion fluid within the isolated placental lobule in our study could affect the interplay between the two forms of TNF- $\alpha$ receptor type I, thereby influencing the response to resveratrol. The involvement of sTNFRSF1A in the pathomechanism of hyperglycemiainduced renal disease was suggested recently in an advanced form of diabetic nephropathy [54].

Moreover, the content of other receptors within the TNF receptor superfamily that are expressed in endothelial cells, such as TNFR2, was not evaluated in this study. TNFR2 exists in a membrane-bound form (mTNFR2) and a soluble form (sTNFR2) and deserves attention because the analyses of TNFRSF1A knockout mice clearly indicated that TNFR2 stimulation alone is sufficient to activate most of the signaling pathways mediated via TNFRSF1A [27].

It is important to highlight that our results are strongly influenced by the experimental model. First and foremost, the circulating blood in the vascular system of the isolated lobule was replaced with perfusion fluid. In this system, the lack of blood, which provides a rich source of cytokines, enabled a more selective and simple interpretation of the observed relationships between CX3CL1/CX3CR1 and TNF- $\alpha$ and TNFRSF $1 \mathrm{~A}$ and NF- $\kappa$ Bp 65 , both at the endothelial cell level and within placental tissue. However, the elimination of cytokines, activated leukocytes, platelets, and insulin circulating in the blood may create an imperfect model that limits the likelihood of the direct implementation of these results in clinical studies [55]. For example, hyperinsulinemia induced by a high-glucose environment enhances the transcriptional activity of NF- $\kappa \mathrm{B}$, while in animal studies, resveratrol has been shown to improve insulin sensitivity, glucose tolerance, and lipid profiles in obese and/or metabolically abnormal animals [42, 56]. Finally, we used hyperglycemic perfusion fluid (HG group) to perfuse placental lobules isolated from women who experienced a normal, nondiabetic pregnancy. Obviously, as a complex metabolic abnormality, diabetes differs from hyperglycemic conditions generated experimentally and studied extracorporeally in a perfused placental lobule. It is likely that gestational diabetes mellitus (GDM), which develops relatively late during pregnancy, best fits our model of a hyperglycemic state. Pathologic changes in the microvasculature of a diabetic placenta, including abnormal angiogenesis and increased vascular density in the more advanced stages of diabetes, may influence cytokine levels and resveratrol activity [57].

In conclusion, because serum levels of CX3CL1 are associated with markers of insulin resistance in gestational diabetes, we investigated the possibility that treatment with resveratrol would decrease the production of both CX3CL1

and TNF- $\alpha$, a strong CX3CL1/CX3CR1 inducer, in placental circulation $[2,8,22,30,31]$. Interestingly, in light of our results, the reported therapeutic effects of resveratrol on reducing hyperglycemia in adults who are obese or who present with type 2 diabetes or impaired glucose tolerance may stem from reductions in CX3CL1 and TNF- $\alpha$ production $[28,58]$. Thus, the anti-inflammatory effects of resveratrol pertaining to $\mathrm{CX} 3 \mathrm{CL} 1 / \mathrm{CX} 3 \mathrm{CR} 1$ signaling in placental circulation are expected to be optimal in pregnant individuals presenting with metabolic disorders under euglycemic conditions. Therefore, adequate control of glucose levels throughout diabetic pregnancy is crucial for obtaining the expected therapeutic effects of resveratrol. Supplementary treatment with resveratrol in diabetic pregnancy has promise to improve endothelial function, placental blood flow, and metabolism. Future studies are needed on diabetic placentae and diabetic pregnant subjects, including those that address safety issues and side effects, especially the potentially harmful actions of resveratrol on fetal pancreatic cells that may lead to their proliferation [59]. The hormetic nature of resveratrol in different types of human cell lines, which manifests as a biphasic dose response with stimulation or beneficial effects at low doses and inhibitory or toxic effects at high doses, must be considered when determining the optimal dose of this compound [60].

\section{Abbreviations}

ADAMs:

ADAM-10:

ADAM-17:

Act:

ALT:

AST:

BDNF:

BLC:

CPU:

CX3CL1:

CX3CR1:

DMSO:

ELISA:

ENA-78:

FGF-4:

G-CSF:

GDM:

GM-CSF:

HG:

IFN- $\gamma$ : IKK:
Desintegrin and metalloproteinases Disintegrin and metalloproteinase (ADAM) 10

Desintegrin and metalloproteinase (ADAM) 17 Serine/threonine kinase Akt (protein kinase $\mathrm{B}, \mathrm{PKB}$ ) Alanine aminotransferase Aspartate aminotransferase Brain-derived neurotrophic factor Chemokine CXCL13 Central processing unit Chemokine CX3CL1 (fractalkine and neurotactin) Chemokine CX3CL1 receptor 1 Dimethyl sulfoxide Enzyme-linked immunosorbent assay Chemokine CXCL5 Fibroblast growth factor 4 Granulocyte colony-stimulating factor Gestational diabetes mellitus Granulocyte-macrophage colony-stimulating factor High glucose Interferon gamma $\mathrm{I} \kappa \mathrm{B}$ kinase complex 


\author{
IL: \\ init CX3CL1: \\ init TNF- $\alpha$ : \\ IP-10:
}

\section{JAK/STAT:}

LPS:

MCP-1-3:

MDC:

MIP- $1 \alpha$, MIP- $1 \beta$, MIP- $1 \delta$ :

$\mathrm{NF}-\kappa \mathrm{B}$ :

NG:

NIK:

NK:

PARC:

PDGF:

PDK1:

PBS:

PI3-kinase:

$\mathrm{pO}_{2}$ :

RANTES:

SCF:

TARC:

TGF- $\beta$ :

TIMP-1-2:

TNFRSF1A:

TNF- $\alpha$, TNF- $\beta$ :

TPO:

VEGF:

V/EVTI:

\section{Interleukin}

Initial concentrations of CX3CL1

Initial concentrations of TNF- $\alpha$

Chemokine CXCL10 (interferon

gamma-induced protein 10;

small inducible cytokine B10)

Janus kinase/signal transducers

and activators of transcription

Lipopolysaccharide

Monocyte chemotactic proteins Macrophage-derived chemokine

Macrophage inflammatory

proteins 1: alpha, beta, delta

Nuclear factor kappa-light-

chain-enhancer of activated B

cells

Normal glucose

$\mathrm{NF}-\kappa \mathrm{B}$-inducing kinase

Natural killer cells

Pulmonary and activation-

regulated chemokine

(chemokine CCL18)

Platelet-derived growth factor

Pyruvate dehydrogenase kinase 1

(pyruvate dehydrogenase

[acetyl-transferring] kinase

isozyme 1)

Phosphate-buffered saline

Phosphoinositide 3-kinase

(phosphatidylinositol-4,5-

bisphosphate 3-kinase)

Oxygen partial pressure

Regulated on activation, normal

T-cell expressed and secreted

(chemokine CCL5)

Stem cell factor

Thymus- and activation-

regulated chemokine

(chemokine CCL17)

Transforming growth factor $\beta$

Tissue inhibitors of

metalloproteinases

Tumor necrosis factor receptor superfamily member 1A (tumor necrosis factor receptor 1 ;

\section{CD120a)}

Tumor necrosis factors: alpha,

beta

Thyroid peroxidase

Vascular endothelial growth

factor

Vascular/extravascular tissular index.

\section{Conflicts of Interest}

The authors declare no conflict of interests, financial, or otherwise.

\section{Acknowledgments}

This research was supported by the internal Grant nos. $2 \mathrm{M} 2 / \mathrm{W} 1 / 14$ and $2 \mathrm{M} 2 / \mathrm{N} 1 / 15$, both founded by the Medical University of Warsaw. No additional external funding was received for this study. The creative contribution to the study design provided by Professor Slawomir Maslinski is gratefully acknowledged.

\section{References}

[1] J. F. Navarro-González and C. Mora-Fernández, "Inflammatory pathways," in Diabetes and the Kidney, K. N. Lai and S. C. W. Tang, Eds., vol. 170pp. 113-123, Contributions to Nephrology, Basel, Karger, 2011.

[2] L. Yao, O. Herlea-Pana, J. Heuser-Baker, Y. Chen, and J. Barlic-Dicen, "Roles of the chemokine system in development of obesity, insulin resistance, and cardiovascular disease," Journal of Immunology Research, vol. 2014, Article ID 181450, p. 11, 2014.

[3] E. Dragomir, I. Manduteanu, M. Calin et al., "High glucose conditions induce upregulation of fractalkine and monocyte chemotactic protein-1 in human smooth muscle cells," Thrombosis and Haemostasis, vol. 100, no. 6, pp. 1155-1165, 2008.

[4] A. Das and S. Mukhopadhyay, "The evil axis of obesity, inflammation and type-2 diabetes," Endocrine, Metabolic \& Immune Disorders Drug Targets, vol. 11, no. 1, pp. 23-31, 2011.

[5] D. Szukiewicz, J. Kochanowski, M. Pyzlak, G. Szewczyk, A. Stangret, and T. K. Mittal, "Fractalkine (CX3CL1) and its receptor CX3CR1 may contribute to increased angiogenesis in diabetic placenta," Mediators of Inflammation, vol. 2013, Article ID 437576, p. 8, 2013.

[6] S. Apostolakis and D. Spandidos, "Chemokines and atherosclerosis: focus on the CX3CL1/CX3CR1 pathway," Acta Pharmacologica Sinica, vol. 34, no. 10, pp. 1251-1256, 2013.

[7] K. Bergmann and G. Sypniewska, "Secreted frizzled-related protein 4 (SFRP4) and fractalkine (CX3CL1) - potential new biomarkers for $\beta$-cell dysfunction and diabetes," Clinical Biochemistry, vol. 47, no. 7-8, pp. 529-532, 2014.

[8] T. Ebert, J. Hindricks, S. Kralisch et al., "Serum levels of fractalkine are associated with markers of insulin resistance in gestational diabetes," Diabetic Medicine, vol. 31, no. 8, pp. 1014-1017, 2014.

[9] R. Shah, S. M. O’Neill, C. Hinkle et al., "Metabolic effects of CX3CR1 deficiency in diet-induced obese mice," PLoS One, vol. 10, no. 9, article e0138317, 2015.

[10] T. V. Fiorentino, A. Prioletta, P. Zuo, and F. Folli, "Hyperglycemia-induced oxidative stress and its role in diabetes mellitus related cardiovascular diseases," Current Pharmaceutical Design, vol. 19, no. 32, pp. 5695-5703, 2013.

[11] I. Mrizak, O. Grissa, B. Henault et al., "Placental infiltration of inflammatory markers in gestational diabetic women," General Physiology and Biophysics, vol. 33, no. 2, pp. 169-176, 2014.

[12] L. Myatt, "Control of vascular resistance in the human placenta," Placenta, vol. 13, no. 4, pp. 329-341, 1992.

[13] C. P. Domingueti, L. M. Dusse, M. D. Carvalho, L. P. de Sousa, K. B. Gomes, and A. P. Fernandes, "Diabetes mellitus: the linkage between oxidative stress, inflammation, hypercoagulability and vascular complications," Journal of Diabetes and its Complications, vol. 30, no. 4, pp. 738-745, 2016. 
[14] M. R. Du, S. C. Wang, and D. J. Li, "The integrative roles of chemokines at the maternal-fetal interface in early pregnancy," Cellular \& Molecular Immunology, vol. 11, no. 5, pp. 438-448, 2014.

[15] E. Dimitriadis, G. Nie, N. J. Hannan, P. Paiva, and L. A. Salamonsen, "Local regulation of implantation at the human fetal-maternal interface," International Journal of Developmental Biology, vol. 54, no. 2-3, pp. 313-322, 2010.

[16] J. M. Bowen, L. Chamley, M. D. Mitchell, and J. A. Keelan, "Cytokines of the placenta and extra-placental membranes: biosynthesis, secretion and roles in establishment of pregnancy in women," Placenta, vol. 23, no. 4, pp. 239-256, 2002.

[17] A. Taki, M. Abe, M. Komaki et al., "Expression of angiogenesis-related factors and inflammatory cytokines in placenta and umbilical vessels in pregnancies with preeclampsia and chorioamnionitis/funisitis," Congenital Anomalies (Kyoto), vol. 52, no. 2, pp. 97-103, 2012.

[18] Y. Pan, C. Lloyd, H. Zhou et al., "Neurotactin, a membraneanchored chemokine upregulated in brain inflammation," Nature, vol. 387, no. 6633, pp. 611-617, 1997, Erratum in: Nature, vol. 389, no. 6646, p. 100, 1997.

[19] J. F. Bazan, K. B. Bacon, G. Hardiman et al., "A new class of membrane-bound chemokine with a CX3C motif," Nature, vol. 385, no. 6617, pp. 640-644, 1997.

[20] A. Ludwig and C. Weber, "Transmembrane chemokines: versatile 'special agents' in vascular inflammation," Thrombosis and Haemostasis, vol. 97, no. 5, pp. 694-703, 2007.

[21] K. W. Kim, A. Vallon-Eberhard, E. Zigmond et al., "In vivo structure/function and expression analysis of the CX3C chemokine fractalkine," Blood, vol. 118, no. 22, pp. e156e167, 2011.

[22] T. Matsumiya, K. Ota, T. Imaizumi, H. Yoshida, H. Kimura, and K. Satoh, "Characterization of synergistic induction of CX3CL1/fractalkine by TNF-alpha and IFN-gamma in vascular endothelial cells: an essential role for TNF-alpha in posttranscriptional regulation of CX3CL1," Journal of Immunology, vol. 184, no. 8, pp. 4205-4214, 2010.

[23] J. G. D'Haese, I. E. Demir, H. Friess, and G. O. Ceyhan, "Fractalkine/CX3CR1: why a single chemokine-receptor duo bears a major and unique therapeutic potential," Expert Opinion on Therapeutic Targets, vol. 14, no. 2, pp. 207-219, 2010.

[24] G. E. White and D. R. Greaves, "Fractalkine: one chemokine, many functions," Blood, vol. 113, no. 4, pp. 767-768, 2009.

[25] B. Chandrasekar, S. Mummidi, R. P. Perla et al., "Fractalkine (CX3CL1) stimulated by nuclear factor kappaB (NF-kap$\mathrm{paB}$ )-dependent inflammatory signals induces aortic smooth muscle cell proliferation through an autocrine pathway," Biochemical Journal, vol. 373, Part 2, pp. 547-558, 2003.

[26] M. J. Sung, D. H. Kim, M. Davaatseren et al., "Genistein suppression of TNF-alpha-induced fractalkine expression in endothelial cells," Cellular Physiology and Biochemistry, vol. 26, no. 3, pp. 431-440, 2010.

[27] L. Cabal-Hierro and P. S. Lazo, "Signal transduction by tumor necrosis factor receptors," Cellular Signalling, vol. 24, no. 6, pp. 1297-1305, 2012.

[28] B. Zarychta, C. G. Gianopoulos, and A. A. Pinkerton, "Revised structure of trans-resveratrol: implications for its proposed antioxidant mechanism," Bioorganic \& Medicinal Chemistry Letters, vol. 26, no. 5, pp. 1416-1418, 2016.

[29] C. Ma, Y. Wang, L. Dong, M. Li, and W. Cai, “Anti-inflammatory effect of resveratrol through the suppression of NF- $\kappa \mathrm{B}$ and JAK/STAT signaling pathways," Acta Biochimica et Biophysica Sinica Shanghai, vol. 47, no. 3, pp. 207-213, 2015.

[30] S. O. Moon, W. Kim, M. J. Sung et al., "Resveratrol suppresses tumor necrosis factor-alpha-induced fractalkine expression in endothelial cells," Molecular Pharmacology, vol. 70, no. 1, pp. 112-119, 2006.

[31] L. Leach, A. Taylor, and F. Sciota, "Vascular dysfunction in the diabetic placenta: causes and consequences," Journal of Anatomy, vol. 215, no. 1, pp. 69-76, 2009.

[32] H. Schneider, K. H. Möhlen, J. C. Challier, and J. Dancis, "Transfer of glutamic acid across the human placenta perfused in vitro," British Journal of Obstetrics and Gynaecology, vol. 86, no. 4, pp. 299-306, 1979.

[33] D. Szukiewicz, J. Kochanowski, T. K. Mittal, M. Pyzlak, G. Szewczyk, and K. Cendrowski, "CX3CL1 (fractalkine) and TNF $\alpha$ production by perfused human placental lobules under normoxic and hypoxic conditions in vitro: the importance of CX3CR1 signaling," Inflammation Research, vol. 63, no. 3, pp. 179-189, 2014.

[34] B. Hoesel and J. A. Schmid, "The complexity of NF- $\kappa$ B signaling in inflammation and cancer," Molecular Cancer, vol. 12, no. 86, pp. 1-15, 2013.

[35] J. Ryu, C. W. Lee, K. H. Hong et al., “Activation of fractalkine/CX3CR1 by vascular endothelial cells induces angiogenesis through VEGF-A/KDR and reverses hindlimb ischaemia," Cardiovascular Research, vol. 78, no. 2, pp. 333-340, 2008.

[36] D. Szukiewicz, M. Wojciechowska, A. Bilska et al., "Aspirin action in endothelial cells: different patterns of response between chemokine CX3CL1/CX3CR1 and TNF- $\alpha /$ TNFR1 signaling pathways," Cardiovascular Drugs and Therapy, vol. 29, no. 3, pp. 219-229, 2015.

[37] X. P. Yang, S. Mattagajasingh, S. Su et al., "Fractalkine upregulates intercellular adhesion molecule-1 in endothelial cells through CX3CR1 and the Jak Stat5 pathway," Circulation Research, vol. 101, no. 10, pp. 1001-1008, 2007.

[38] D. Szukiewicz, A. Szukiewicz, D. Maslinska, G. Szewczyk, and G. M. Watroba, "Mast cell-derived vascular endothelial growth factor (VEGF) and microvascular density in diabetic placentae," Inflammation Research, vol. 52, Supplement 1, pp. S9S10, 2003.

[39] D. Szukiewicz, A. Szukiewicz, D. Maslinska, and M. W. Markowski, "Placental mast cells (MC) and histamine (HA) in pregnancy complicated by diabetes class $\mathrm{C}$ - relation to the development of villous microvessels," Placenta, vol. 20, Supplement 1, pp. 503-510, 1999.

[40] B. Huppertz, E. Abe, P. Murthi, T. Nagamatsu, D. Szukiewicz, and C. Salafia, "Placental angiogenesis, maternal and fetal vessels-a workshop report," Placenta, vol. 28, Supplement A, pp. S94-S96, 2007.

[41] D. Bonnefont-Rousselot, "Resveratrol and cardiovascular diseases," Nutrients, vol. 8, no. 5, pp. 1-24, 2016.

[42] T. Szkudelski and K. Szkudelska, "Anti-diabetic effects of resveratrol," Annals of the New York Academy of Sciences, vol. 1215, no. 1, pp. 34-39, 2011.

[43] P. K. Bagul, N. Deepthi, R. Sultana, and S. K. Banerjee, "Resveratrol ameliorates cardiac oxidative stress in diabetes through deacetylation of NFkB-p65 and histone 3," Journal of Nutritional Biochemistry, vol. 26, no. 11, pp. 1298-1307, 2015.

[44] L. Lattenist, P. Ochodnicky, M. Ahdi et al., "Renal endothelial protein $\mathrm{C}$ receptor expression and shedding during diabetic 
nephropathy," Journal of Thrombosis and Haemostasis, vol. 14, no. 6, pp. 1171-1182, 2016.

[45] L. A. Hurst, R. A. Bunning, B. Sharrack, and M. N. Woodroofe, "siRNA knockdown of ADAM-10, but not ADAM-17, significantly reduces fractalkine shedding following proinflammatory cytokine treatment in a human adult brain endothelial cell line," Neuroscience Letters, vol. 521, no. 1, pp. 52-56, 2012.

[46] Y. Kikuchi, R. Ikee, N. Hemmi et al., "Fractalkine and its receptor, CX3CR1, upregulation in streptozotocin-induced diabetic kidneys," Nephron Experimental Nephrology, vol. 97, no. 1, pp. e17-e25, 2004.

[47] K. V. Ramana, B. Friedrich, S. Srivastava, A. Bhatnagar, and S. K. Srivastava, "Activation of nuclear factor $-\kappa B$ by hyperglycemia in vascular smooth muscle cells is regulated by aldose reductase," Diabetes, vol. 53, no. 11, pp. 2910-2920, 2004.

[48] A. D. Jagdale, L. N. Bavkar, T. A. More, M. M. Joglekar, and A. U. Arvindekar, "Strong inhibition of the polyol pathway diverts glucose flux to protein glycation leading to rapid establishment of secondary complications in diabetes mellitus," Journal of Diabetes and its Complications, vol. 30, no. 3, pp. 398-405, 2016.

[49] V. Ciddi and D. Dodda, "Therapeutic potential of resveratrol in diabetic complications: in vitro and in vivo studies," Pharmacological Reports, vol. 66, no. 5, pp. 799-803, 2014.

[50] S. Mitchell, J. Vargas, and A. Hoffmann, "Signaling via the $\mathrm{NF} \kappa \mathrm{B}$ system," Wiley Interdisciplinary Reviews: Systems Biology and Medicine, vol. 8, no. 3, pp. 227-241, 2016.

[51] A. Jawerbaum and E. González, "Diabetic pregnancies: the challenge of developing in a pro-inflammatory environment," Current Medicinal Chemistry, vol. 13, no. 18, pp. 2127-2138, 2006.

[52] T. R. Magee, M. G. Ross, L. Wedekind, M. Desai, S. Kjos, and L. Belkacemi, "Gestational diabetes mellitus alters apoptotic and inflammatory gene expression of trophoblasts from human term placenta," Journal of Diabetes and its Complications, vol. 28, no. 4, pp. 448-459, 2014.

[53] H. Z. Ozsoy, N. Sivasubramanian, E. D. Wieder, S. Pedersen, and D. L. Mann, "Oxidative stress promotes ligandindependent and enhanced ligand-dependent tumor necrosis factor receptor signaling," Journal of Biological Chemistry, vol. 283, no. 34, pp. 23419-23428, 2008.

[54] G. Fernández-Juárez, J. V. Perez, J. L. Fernández et al., "High levels of circulating TNFR1 increase the risk of all-cause mortality and progression of renal disease in type 2 diabetic nephropathy," Nephrology (Carlton), vol. 22, no. 5, Article ID 12781, pp. 354-360, 2017.

[55] H. Umehara, E. T. Bloom, T. Okazaki, Y. Nagano, O. Yoshie, and T. Imai, "Fractalkine in vascular biology: from basic research to clinical disease," Arteriosclerosis, Thrombosis, and Vascular Biology, vol. 24, no. 1, pp. 34-40, 2004.

[56] I. Golovchenko, N. L. Goalstone, P. Watson, M. Brownlee, and B. Draznin, "Hyperinsulinemia enhances transcriptional activity of nuclear factor- $\kappa \mathrm{B}$ induced by angiotensin II, hyperglycemia, and advanced glycosylation end products in vascular smooth muscle cells," Circulation Research, vol. 87, no. 9, pp. 746-752, 2000.

[57] S. Cvitic, G. Desoye, and U. Hiden, "Glucose, insulin, and oxygen interplay in placental hypervascularisation in diabetes mellitus," BioMed Research International, vol. 2014, Article ID 145846, p. 12, 2014.
[58] S. Timmers, E. Konings, L. Bilet et al., "Calorie restriction-like effects of 30 days of resveratrol supplementation on energy metabolism and metabolic profile in obese humans," Cell Metabolism, vol. 14, no. 5, pp. 612-622, 2011.

[59] V. H. Roberts, L. D. Pound, S. R. Thorn et al., "Beneficial and cautionary outcomes of resveratrol supplementation in pregnant nonhuman primates," FASEB Journal, vol. 28, no. 6, pp. 2466-2477, 2014.

[60] E. J. Calabrese, M. P. Mattson, and V. Calabrese, "Dose response biology: the case of resveratrol," Human \& Experimental Toxicology, vol. 29, no. 12, pp. 1034-1037, 2010. 


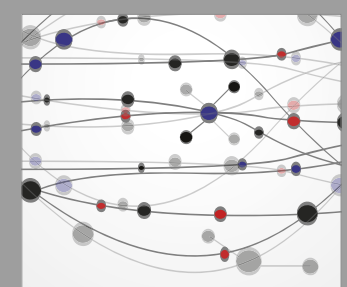

The Scientific World Journal
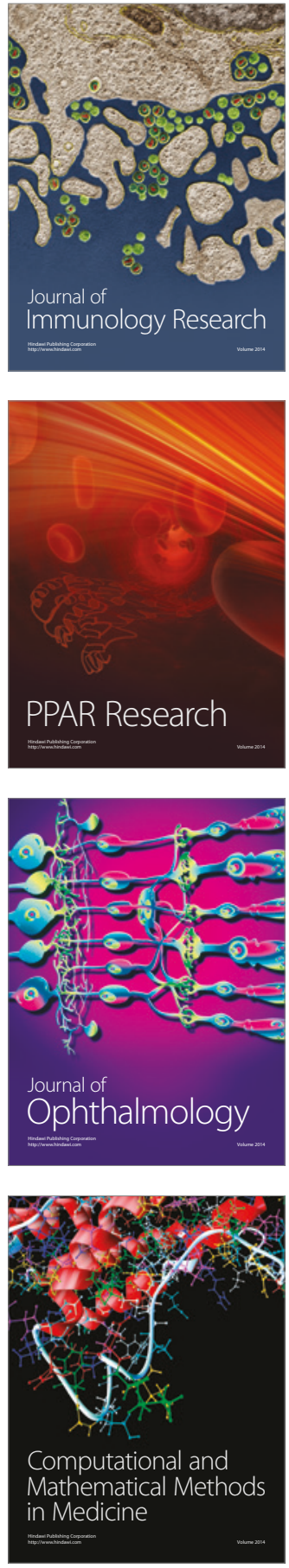

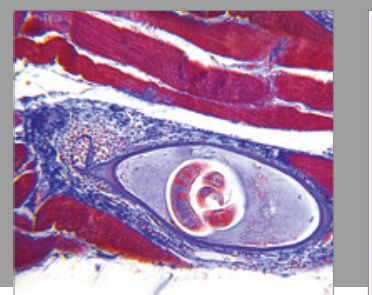

Gastroenterology Research and Practice
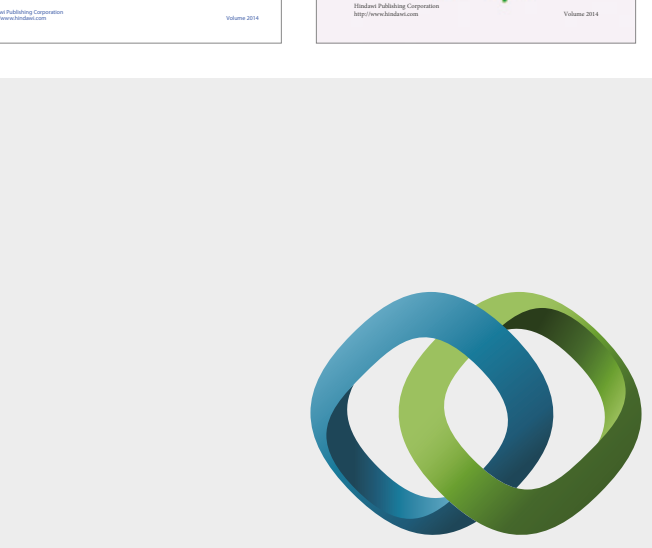

\section{Hindawi}

Submit your manuscripts at

https://www.hindawi.com
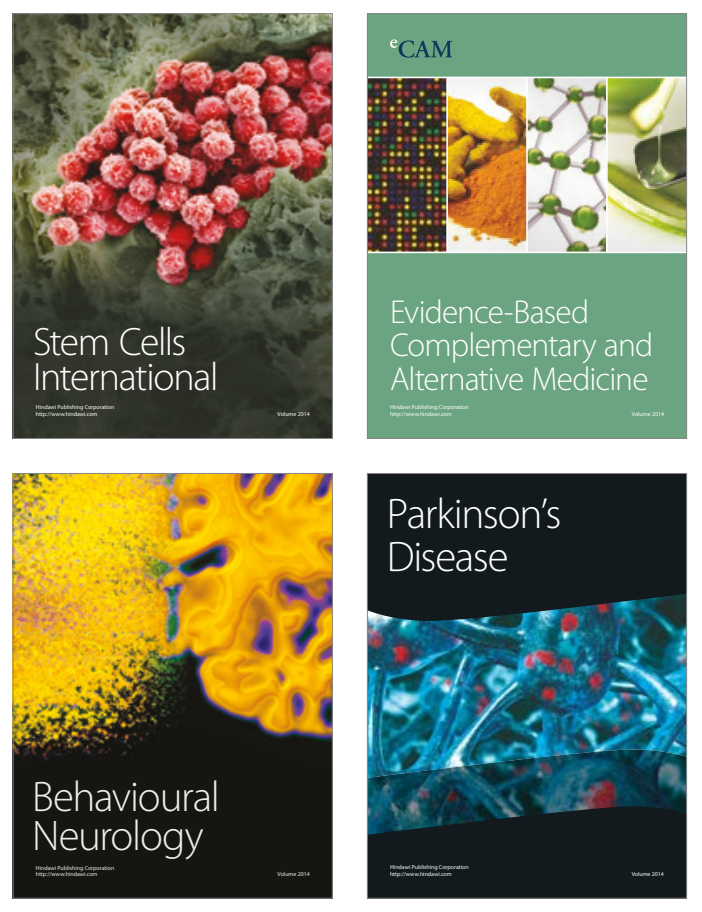
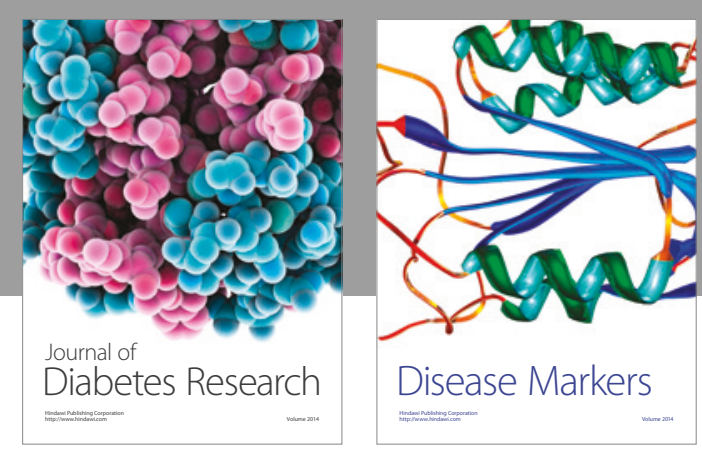

Disease Markers
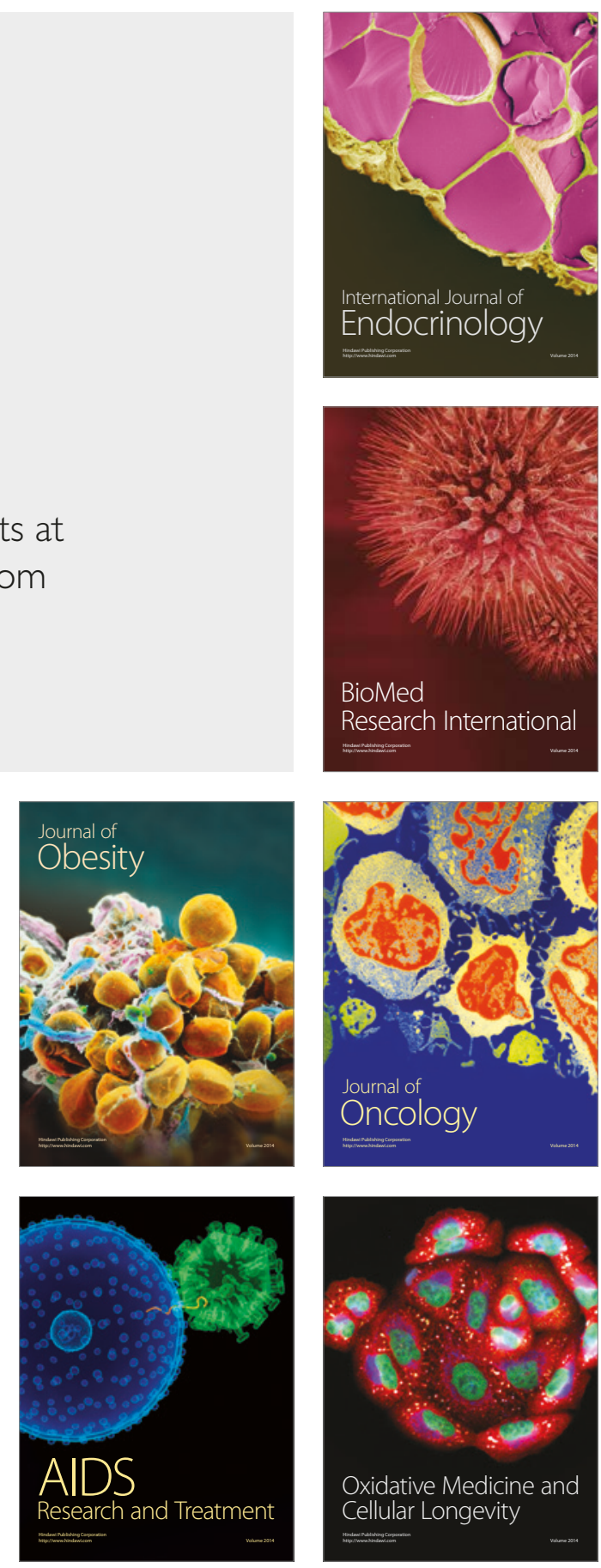